\title{
REFERENCIAS AL CULTO PRECRISTIANO DEL MONTE BILIBIO (LA RIOJA)
}

\author{
Andoni Sáenz de Buruaga*
}

Resúmen: El hallazgo en la parte meridional de Álava, en las proximidades de La Rioja, de un ara votiva de época romana con el teónimo Baelibio, además de replantear anteriores lecturas sobre otro ejemplar ya conocido del lugar, suscita derivados comentarios acerca de su posible conexión con el actual orónimo de Bilibio emplazado en aquel mismo contexto espacial (Haro, La Rioja). En este sentido, sugerimos su vinculación con el culto naturalista de los montes. Diversos indicios y testimonios $-a$ veces de heterógenea trascendencia tempora-documentados en el ambiente próximo, pudieran justificar la hipótesis propuesta.

RÉSUMÉ: La découverte à la partie méridionale de l'Álava, au proximité de La Rioja, d'un autel votif d'époque romaine avec le théonyme Baelibio pose à nouveau anciennes lectures faites sur autre exemplaire connu du même endroit, et, complémentairement, fait établir quelques commentaires sur sa possibilité de liaison avec l'oronyme actuel de Bilibio, présent dans l'espace proche (Haro, La Rioja). En ce sens, nous proponsons leur rapport avec le culte des montagnes. Indices et témoins divers-quelques fois de signification temporelle hétérogène- documentés à ce contexte géographique, peuvent justifier l'hypothèse.

En un addenda al artículo titulado Nuevas inscripciones de época romana en Álava ( SÁENZ DE BURUAGA, 1988), dábamos cuenta del hallazgo de un epígrafe romano en la ermita de San Bartolomé en Angostina (Álava) que incorporaba, como dato más significativo, el teónimo Baelibio ( dat.).

\footnotetext{
* Departamento de Geográfia, Prehistoria y Arqueología. Universidad del País Vasco. Vitoria-Gasteiz
} 
La práctica integridad y favorable conservación del nombre despejaban, a priori, cualquier tipo de duda acerca de su lectura. El hecho era interesante porque de manera más inmediata podía incidir sobre la lectura de otro teónimo -a saber, fracturado parcialmente- descubierto con anterioridad en las mismas paredes de esta ermita. Además, consecuencia de ello, a nadie, medianamente conocedor de estas latitudes, se ocultaba la coincidencia etimológica entre aquel nombre y el toponímico, relativamente próximo, de Bilibio.

\section{El Ara a Baelibio en el Repertorio Epigráfico de la Ermita de San BARTOLOMÉ}

El monumento fue descubierto el día 1 de Mayo de 1988 por Edurne Domínguez Aguirre y $\mathrm{M}^{\mathrm{a}}$ Carmen Ros formando parte de la clave superior de una ventana emplazada en la pared meridional de la ermita de San Bartolomé en Angostina' (fig.1).

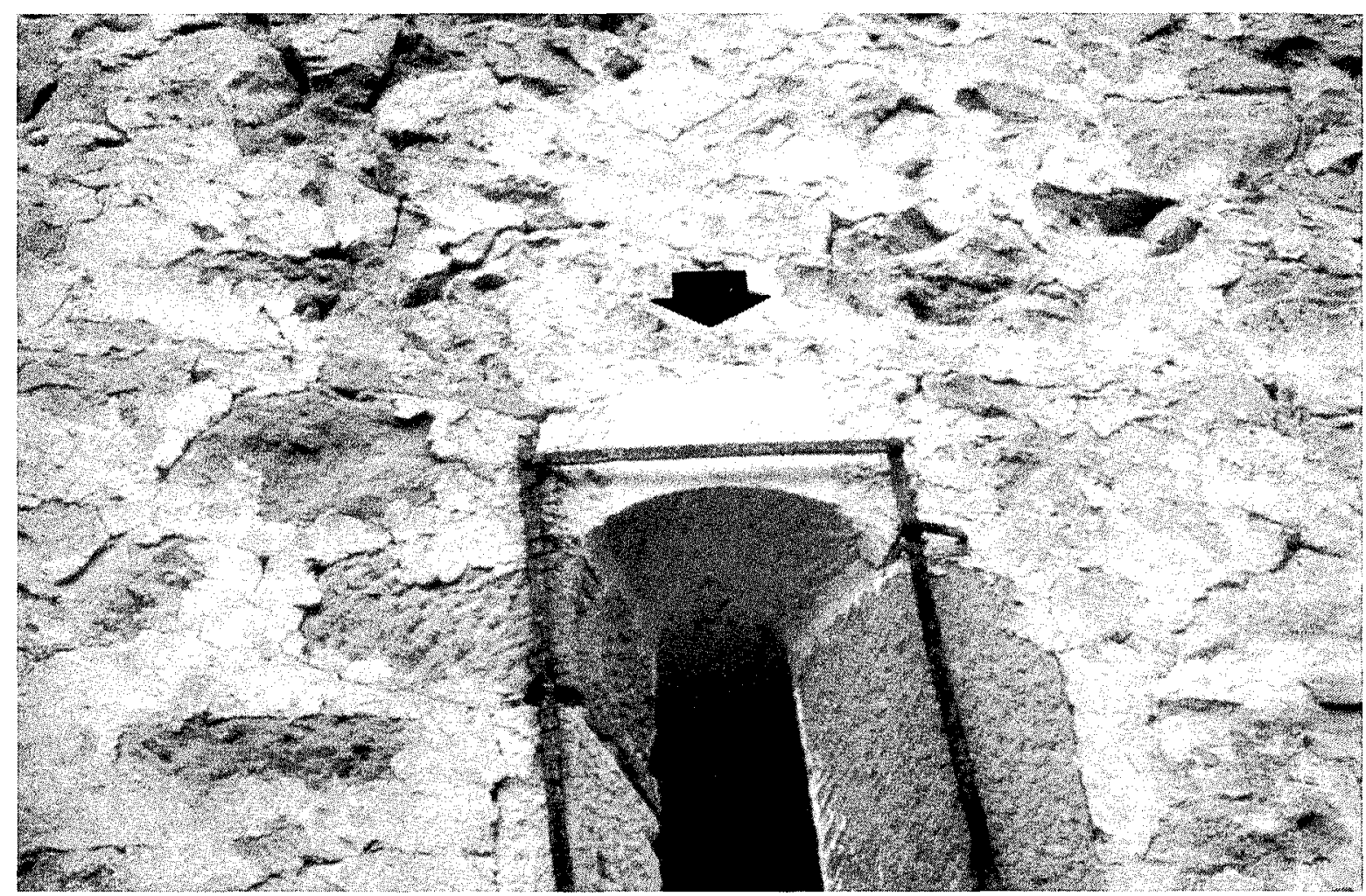

La nueva inscripción a Baelibio en un ventanal de la ermita de San Bartolomé (Angostina, Álava).

1. A juicio de M. Portilla y J. Eguía ( 1968, pp. 255s) la mayor parte de la actual ermita de San Bartolomé en Angostina debió edificarse hacia el siglo XIII; de cronología posterior datan un ábside poligonal - probablemente de fines del XVI, quizás en torno a la reparación de la misma de 1566 - y el retablo - éste propiamente del XVII-.

Por otra parte, advocaciones a San Bartolomé se conocen además en, al menos, un par de ermitas ubicadas, como en el caso de Angostina, en el entorno inmediato de la Sierra de Cantabria / Toloño: una al SW. de Lagrán (Álava), en las estribaciones septentrionales de Cantabria, en torno a la vertical de Palomares y Recilla ; y, otra, al E. de Rivas de Tereso (La Rioja), en las estribaciones meridionales de Toloño, próxima a la vertical de la Peña Colorada. 
Merced a su desinteresada disposición pudimos verificar el hallazgo el día 7 del mismo mes y año; aprovechando la ocasión tomamos una serie de datos analíticos del mismo, así como el levantamiento de un calco y varias tomas fotográficas.

Se trata de un fragmento de ara votiva, aparentemente de cuerpo prismático y tendencia rectangular, de $(0,38)$ x $(0,26)$ x $0,17 \mathrm{~m}$. El campo epigráfico máximo disponible alcanza los $(0,12) \times(0,17) \mathrm{m}$. Las letras, de buena factura, responden uniformemente a un módulo tipométrico de $3,00 \mathrm{~cm}$, incorporando en algún caso -concretamente, en la última línea de texto - signos de interpunción a base de hedera. Hay presencia de líneas guía en el primer renglón conservado y existen fracturas parciales de B (1.1, in), O (1.1), V (1.3) y M (1.3).

[- - ] Baelibio

$[---]+$ TEA A [- - - ]

$\mathrm{u}$ ( otum) s ( oluit) 1 ( ibens ) $\mathrm{m}$ ( erito)

En 1.2 existen restos de una letra que quizás pudiera corresponder a parte de una $\mathrm{N}$ (fig.2).

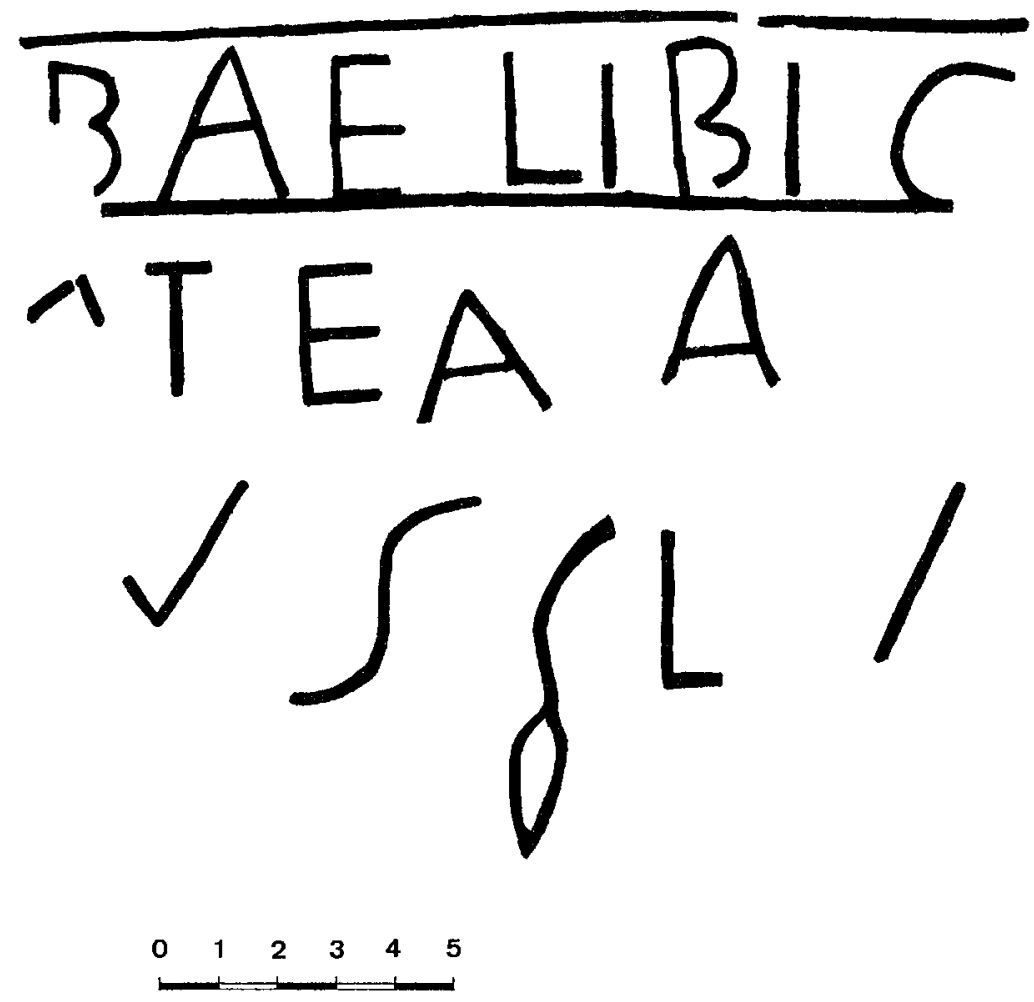

Calco de la nueva inscripción a Baelibio

Además de este ejemplar, la ermita de San Bartolomé ha proporcionado otros siete monumentos epigráficos más: se tratan de tres estelas funerarias, dos lápidas votivas, una lápida funeraria y un ara. 
En la mayor parte de los casos han sido reutilizados como materiales constructivos, encontrándose emplazados actualmente en las paredes exteriores del templo: excepción a la regla la constituye un ejemplar que habiendo formado parte del ángulo de la mesa del altar fue trasladado alrededor de 1912 al Instituto de Vitoria, lugar en el que se encontraba el Museo Incipiente, y que puede contemplarse en la actualidad en las dependencias del Museo de Arqueología de Alava, en Vitoria.

Un total de cinco de ellos fueron descubiertos por F. Baráibar, bien a fines del siglo XIX o principios del presente (Baráibar, F.s.f., Ms. Angostina; id. 1912, pp. 13)2, siendo incorporados, posteriormente, uno más por Elorza (1970, pp. 238, nº, foto 6) -si bien únicamente con carácter anepigráfico- y finalmente, además de definir el resto precedente como epigráfico, otro más por nosotros mismos (SÁENZ DE BURUAGA, 1988: $534 \mathrm{ss}, \mathrm{n}^{\circ} 1,2$, fotos 1, 2, 3).

Además del análisis descriptivo de estos monumentos -especialmente, cf. BARÁIBAR, ANGOSTINA; id. 1912; ELORZA, 1967; id. 1970; SÁENZ DE BURUAGA, 1988-, incorporado en algunos casos en diversos repertorios - $c f$. CASTRO, 1915; CORTA, 1928; FERNÁNDEZ MEDRANO, 1948; VIVES, 1971; VV. AA. 1987-, se cuenta con datos relativos a la onomástica de algunas producciones -en especial, $c f$. ALBERTOS, 1970; id. 1984 b-.

Desde esta última perspectiva puede decirse que en el repertorio de Angostina existen producciones individualizadas con antropónimos exclusivamente indígenas (Ambatus, Andio, Madicena), únicamente romanos (Aemilius, Maternus, Floru; Marcus, Vibius, Flauinus, Vibia, Marcella;....) y otros combinados (Flauos, Andio).

De todo el conjunto epigráfico, y en concordancia con el objeto de este trabajo, el monumento que más nos interesa es una lápida votiva que incorpora el teónimo Baelisto (dat.).

El ejemplar en cuestión fue descubierto por Baráibar quien ofreció una primera y única interpretación (BARÁIBAR, ANGOSTINA) que sería mantenida por aquellos que con posterioridad lo describieron (ELORZA, 1967, 126, n 7; VIVES, 1971: ILER 6780) o profundizaron en algún aspecto concreto (ALBERTO, 1970; id. 1984 b ; ELORZA, 1972).

El texto de Baráibar establecía la siguiente lectura: Flavos [Andio ?] / nis fi ( lius )/Baelisto v (otum) $s$ (olvit) $l$ ( ibens) $m$ ( erito).

2. Ninguna de las producciones se halla recogida en el CIL II de 1869 ni en el Supplementum de 1892. De haberse conocido en estas fechas no cabe duda que hubieran formado parte del Corpus, pues F. Baráibar, su descubridor, era en esos momentos el colaborador oficial de E. Hübner, y encargado de la recopilación del repertorio epigráfico en tierras alavesas, para la redacción del Corpus Inscriptionum Latinarum.

Los cinco ejemplares aparecen recogidos de forma individualizada en los manuscritos personales de Baráibar y solamente uno de ellos - precisamente el que se trasladó a Vitoria - se encuentra documentado en la bibliografía impresa de 1912, dentro de un trabajo que Baráibar realizó a propósito de la creación del Museo Incipiente en esta ciudad. El conocimiento de este ejemplar induce a hacerlo extensivo a los otros cuatro, de ahí que 1892 y 1912 marquen los límites máximos del espacio temporal en que Baráibar llevó a cabo los descubrimientos epigráficos de Angostina 
Aceptando en su inmensa mayoría la lectura de Baráibar, un análisis in situ del texto nos ponía de manifiesto la existencia de fracturas parciales de determinadas letras: en la primera línea la $\mathrm{S}$, en la segunda la I más exterior y la mayor parte del tercer renglón, concretamente una buena parte del sufijo -IST- y el total de la fórmula del voto -VSLM-

Si a este hecho, que bien pudiera justificar la confusión de $\mathrm{B}$ por $\mathrm{S}$ y de I por $\mathrm{T}$, añadimos el derivado de la presencia del nuevo epígrafe en donde se advierte, sin dudas, el rótulo Baelibio, creemos tener los argumentos necesarios para corregir la lectura de Baelisto por la de Baelibio. De esta forma la lectura del epígrafe respondería a:

Flâuos [ Andio]

nis fí ( lius) • [- - - ]

Baelibio u (otum) s ( oluit) 1 ( ibens) m ( erito)

En conclusión, debe aceptarse la existencia del teónimo Baelibio -documentado en dos ocasiones en el repertorio epigráfico en la ermita de San Bartolomé de Angostina - y suplantarse por tal la antigua lectura de Baelisto (fig.3).

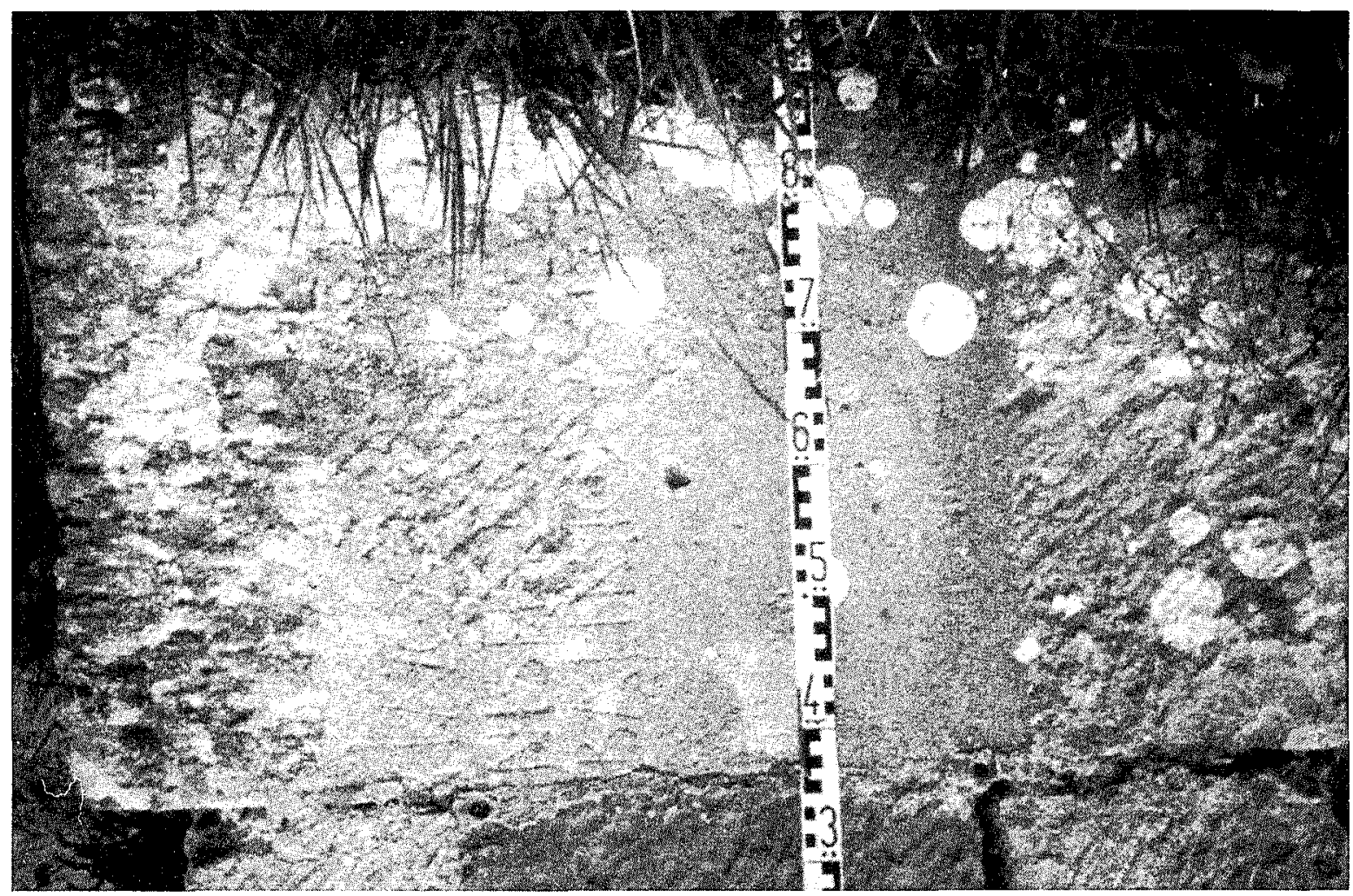

La antigua inscripción a Baelibio en la misma ermita de Angostina.

2. ACERCA DE LA POSIBLE SIGNIFICACIÓN DE BAELIBIO: LA SACRALIZACIÓN DEL MONTE BILIBIO

Albertos, con relación al teónimo Baelisto se inclinaba por la vinculación del radical con el ide. *bhel "blanco, brillante" y el valor superlativo del sufijo a través del ilirio -sto, de tal suerte que Baelisto sería sinónimo de "el más brillante", es decir 
del sol, equiparable en este sentido a Apollo Belenos (ALBERTOS, 1970: 157 s) ${ }^{3}$. Descartando la posibilidad de un Beles ibérico /Belex aquitano (o del euskérico Beltz) -que acertadamente Caro Baroja (1973: 119) relacionaba con Ubeltesonis, mejor Beltesonis de acuerdo con la lectura de Barandiarán (1968), de la lápida de Oyárzun (Guipúzcoa) y con Aherbelste deo del Pirineo francés-, la presencia significada de antropónimos indoeuropeos en la zona constituiría complementariamente, para la citada Albertos, un argumento de base para llevar a cabo la reducción propuesta.

La hipótesis de Albertos aparecería recogida en la mayor parte de las posteriores referencias escritas al respecto (ELORZA, 1972: 363; BLÁZQUEZ, 1975: 43; RAMÍREZ, 1981: 228).

Dejando al margen -por lo dificultoso y problemático del encomio- las supuestas vinculaciones del teónimo con el indoeuropeo ${ }^{4}$, y por lo que respecta a una perspectiva espacial más inmediata, sí podemos presentar como verosímil su vinculación etimológica con el toponímico Bilibio a través de una evolución normal Baelibio> *Belibio > Bilibio.

Además de etimológicamente, la conexión Baelibio/ Bilibio se ofrece como altamente interesante por lo que compete a su ubicación en un espacio físico específico, a los diversos niveles de poblamiento vinculados directamente a ese contexto y, prioritariamente, a su concepción como exponente o manifestación cultural de una realidad trascendente.

\subsection{El Espacio Físico.}

La ermita de San Bartolomé en Angostina, en donde se encuentran actualmente las dos referencias epigráficas a Baelibio, se halla situada en las estribaciones nororientales de las denominadas sierras de Cantabria y Toloño, en torno a la vertical de la peña de Lapoblación (1243 m.). Dichas sierras no son más que una misma alineación montañosa uniforme desde el punto de vista estructural y litológico que emplazada, sin solución de continuidad, y aproximadamente en orientación E. a W., en la

3. La identificación entre Apolo y Belen fue ya puesta de manifiesto por Dontenville ( 1948 , pp. 89ss). De igual manera, la creencia en Belen - Apolo no compete sólo a celtas y greco-romanos sino que parece haber formado parte ya de lo pre-indoeuropeo: "... La vérité est que Belen-Apollon est, a été le Grand Dieu des Germains comme des Celtes et avant eux, de populations pré-indo-européennes..." ( Op. cit. supra, pp. 93). La tradición céltica, por su parte, consagrará montañas y rocas al Apolo celta, a Belen, como manifestaciones externas del culto solar: "...Le soleil, et spécialement le soleil ascendent ou levant, sera donc par les multitudes surdéterminations, de l'élévation et de la lumière, du rayon et du doré, l'hypostase par excellence des pouissances ouraniennes. Apollon serait le dieu <<hyperboréen >> type, dieu des envahisseurs indo-européens, l'héliolatrie triomphant à l'époque hallstatienne en même temps que le culte du feu et du ciel... Bel, Belen ou Belinus signifierait $<<$ brillant, resplendissant $>>\ldots$ Ce serait bien le vieux mot Belen qui sans équivoque désignerait le soleil...." (DURAND, 1984: 167).

4. La raíz*bal/*bel, asimilada a la idea de altura, piedra, roca, elevación del terreno - *pala/*bala, "pic de montagne" ( $c f$. BERTOLDI, 1931: 138ss) -, además de formar parte de la toponimia francesa de tradición céltica - la "toponymie bélénique" ( $c f$. DONTENVILLE, 1948: 91-96) - se halla igualmente vinculada, como el mismo culto a Belen (vid. nota 3), a topónimos pre-galos - el caso de la Lozère ( $c f$. FLUTRE, 1957: 28 ) y genéricamente pre-indoeuropeos - el caso de la Provenza ( $c f$. ROSTAING, 1950: 78s, 82) -. 
parte meridional del territorio histórico de Álava, separa, siempre con fuertes y mayores desniveles la meridional comarca de La Rioja Alavesa, y con ello estrictamente la fosa tectónica del Ebro, de los valles septentrionales de la Montaña Alavesa e inmediato Condado de Treviño.

Esta alineación de Cantabria/ Toloño, con alturas superiores en muchos tramos a los $1200 \mathrm{~m}$. y cuyo techo se alcanza en Palomares (1436 m.), tiene su prolongación hacia oriente, entre parte de Alava y Navarra, por la sierra de Codés y hacia occidente, una vez salvado el Ebro en el paso de las Conchas de Haro, por tierras de La Rioja y Burgos, a través de los montes Obarenes. En cualquiera de los casos se trata de conjuntos tectónica y litológicamente homogéneos (GALDOS, RUÍZ URRESTARAZU, 1983:.55-60).

A poco más de $30 \mathrm{Km}$. en línea recta al W. de la ermita de San Bartolomé y sobre la cluse de las Conchas de Haro, formando parte del extremo más oriental de los Obarenes, se halla el monte Bilibio (Haro, La Rioja), más conocido actualmente por San Felices merced a su elección como morada por este ermita cristiano durante los siglos $\mathrm{V}$ y $\mathrm{VI}^{5}$.

Si bien su cota de altitud -aproximadamente en torno a los $640 \mathrm{~m}$.- dista mucho de algunas de las documentadas en esa misma alineación, su ubicación a modo de fortaleza natural sobre el Ebro unido a la verticalidad de sus paredes en ese flanco oriental -hasta los $200 \mathrm{~m}$. por encima del actual cauce- hacen de Bilibio un lugar emblemático y digno de mención ${ }^{6}$ (fig. 4, ver pág. siguiente).

El toponímico Bilibio aparece documentado ya desde antiguo: San Braulio (575651), obispo de Zaragoza en la Vita Sancti Aemiliani, se refiere sin duda alguna al promontorio como castellum Bilibium (VÁZQUEZ DE PARGA, 1943, 9: 14), lo cual parece de por sí suficientemente elocuente ${ }^{7}$. Por otra parte, en el Cartulario de San Millán

5. Acerca de la historia de Bilibio es interesante la consulta del Diccionario Geográfico-Histórico de la Real Academia de la Historia (1802, pp. 180s), suponiendo un resumen del mismo la cita recogida en el Diccionario Geográfico-Estadístico-Histórico de España y sus posesiones de ultramar de P. Madoz (1846, pp. 340s), reimpreso recientemente en lo relativo a Álava - que es donde se encuentra la cita de Bilibio- por las Juntas Generales de este territorio histórico (SÁNCHEZ ZURRO, 1989: 107), además de la referencia concreta de Bilibio en el apunte que sobre Haro realiza Govantes (1846:.85ss ) dentro del volumen riojano del Diccionario Geográfico-Histórico de España. Configurarían el apartado el trabajo, en parte inmerso en la fantasía de Hergueta ( 1906), la aportación hagiográfica de Cantera Orive ( 1955) y, en especial, la más reciente recopilación histórica de Cegarra ( 1990).

6. Merced a la morfología del paso de las Conchas de Haro - configurado por Bilibio frente al que se encuentra el castro de Buradón y entre ambos el Ebro - se ha pretendido derivar el topónimo por corrupción del latín bilabium (VILLACAMPA, 1980: 69). Hergueta, por su parte, fue mucho más lejos cuando escribió: “... Los griegos fundaron varias estancias en süs orillas, una de ellas Bilibio, en su lengua dos rocas o entre dos riscos por estar situado en la misma boca del Ebro entre las dos conchas por cuya circunstancia creen algunos sin fundamento que el nombre de Bilibio viene por corrupción del Bilabium por ser como dos labios que toca y lame el agua del río..." (HERGUETA, 1906: 18). Merino Urrutia llegó a decir que se llamó Bis Labium o " nombre que se dio al estrecho paso del Ebro por el lugar que hoy se llama Las Conchas..." (MERINO URRUTIA, 1977: 282)

7. A propósito del topónimo, en una lápida funeraria del Monasterio de San Millán de Suso (La Rioja), extraída el año 1601 del antiguo sepulcro de San Millán y que a juicio de Govantes (1846, pp. 86) " sin duda 


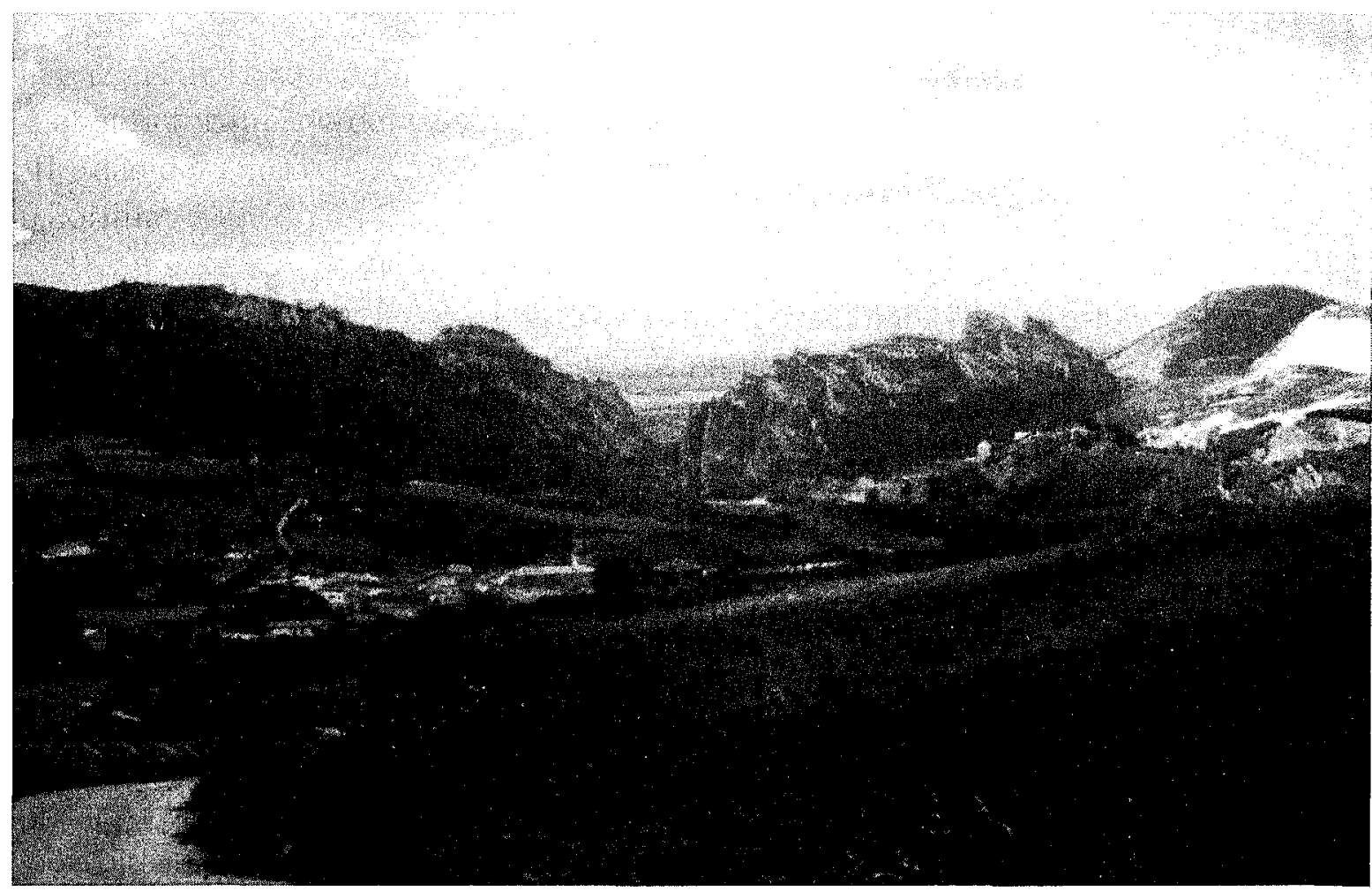

El paso de las Conchas de Haro desde las proximidades de Salinillas de Buradón (en la parte anterior de la foto): a la derecha Bilibio, a la izquierda Buradón.

de la Cogolla aparece nominado como Billivio en un documento datado en el año $934^{8}$; de creer a Govantes (1846: 163) "el monge que escribió la historia de la traslación de los restos de San Felices en el siglo XI-concretamente el día octavo de los idus de Noviembre de la era 1128 (= 6 de Noviembre del año 1090) - repite una infinidad de veces el nombre de Bilibio de la misma manera que le escribió San Braulio"; en la ya señalada lápida del antiguo sepulcro de San Millán donde se menciona el castellum Bilibiense (vid. nota 7) ; y, ya en el fuero de Miranda de Ebro de 1099 definitivamente

se puso esta lápida cuando murió el santo confesor en la era 612, que en la misma se expresa", se hacía referencia al castellum Bilibiense como lugar al que se dirigió el santo con el fin de tener por maestro al confesor Felices: “...ad castellum Bilibiense (quod decem et quinque milliaria à supra nominato oppido distat et duodecim à Tritio) ut magisterio Felicis confesoris uteretur..." (GOVANTES 1846: 164).

Por otra parte, el hecho de que allí tuviera su habitáculo el eremita San Felices, así como el empleo del epíteto castellum ya en los textos de San Braulio (VÁZQUEZ DE PARGA, 1943: 14 ; - en este sentido, cf. tb., siguiendo a T. Minguella, los comentarios a la obra de San Braulio de Lynch y Galindo (1950, cap. IX La vida de San Emiliamo, pp. 255-278-, pp. 268) - se han barajado como argumentos suficientes para negar entidad de población a Bilibio al menos en el siglo V (VILLACAMPA, 1980: 69): si bien el calificativo manejado no debe condicionar la afirmación propuesta - incluso, menos arriesgado pudiera suponer lo contrario -, la existencia del hasta ahora único, pero no por ello definitivo, eremitorio de San Felices, no debe ser excluyente de un núcleo de habitación en el mismo contexto de Bilibio.

8. Se trata de un texto por el cual el Conde Fernán González de Castilla concede al Monasterio de San Millán de la Cogolla que reciba un censo en todas las poblaciones y regiones de su condado y que por lo que aquí respecta señala concretamente: “....Termino, Cellorico, Billivio, Burbon iste predicte cum suis villis ad suas alfoces pertinentibus, carneros; domus octo faciunt se ad unum..." (UBIETO ARTETA, 1976, doc. 22, pp. 38). 
como Bilibio ${ }^{9}$, de la misma forma que lo haría en el fuero que Alfonso VIII concedería a la villa de Haro en 1187 y en otras muchas posteriores escrituras. Con lo cual tal y como señaló Govantes (1846: 163) : "Se ha dicho que hoy, y siempre, se llamó y llama Bilibio, porque cabalmente hay una infinidad de documentos que lo prueban".

Con todo ello, ponderando suficientemente las circunstancias del depósito secundario de los textos epigráficos relativos a Baelibio, así como la cronología del manuscrito de referencia al topónimo Bilibio, puede establecerse común denominador de ambos a la alineación montañosa de Cantabria / Toloño.

\subsection{Referencias Arqueológicas}

De cara a rastrear sus posibles vinculaciones para con algunos grupos humanos será menester el centrar la atención en los documentos arqueólogicos relativos, lógicamente, a la romanización y a los precedentes de poblamiento inmediatos a la misma.

Si en el mismo Bibilio la prospección arqueológica ha puesto de manifiesto la existencia de testimonios propios, genéricamente, de la Edad del Hierro, de tal suerte que vendrían a configurarlo como un poblado fortificado indígena ${ }^{10}$, inmediatamente encima de la ermita de San Bartolomé se asienta otro castro fortificado, el de Cividad (Angostina, Álava), donde tras un sondeo estratigráfico se recuperaron indicios arqueólogicos asignables, inicialmente, a la I Edad del Hierro (Carta Arqueológica de Álava-CAA- : doc. 3515, pp. 250).

Desde esta misma perspectiva, entre uno y otro, vinculados directamente a la sierra de Cantabria / Toloño y a sus estribaciones más inmediatas, se tiene constancia de una serie de asentamientos que participan de ambientes indígenas propios de la Edad del Hierro: tomando como fuente documental la Carta Arqueológica de Álava (CAA) atestiguan el hecho los casos, de W. a E., del Castro de Buradón (Salinillas

9. La cita está tomada de Govantes (1846: 86) y en ella se escribe por relación a los términos jurisdiccionales en dicho fuero de Miranda de Ebro: “...Et cum alfocibus quae fuerunt de Cellorigo de Bilibio qui sint de Miranda, et de Cellorigo, et de Bilibio quae remanent in se... Et Ebro versus sursum sub Bilibio totus Ebro, interius eundo, usque dum junguntur Zadorra et Ebro..."

10. Con relación a los hallazgos arqueológicos de Bilibio, además del eremitorio de San Felices e inmediato castillo, sólo se tenía noticia de la existencia de una necrópolis ubicada en la zona baja, mas, en cualquier caso de cronología "bastante tardía" (MERINO URRUTIA, 1946: 359), finalmente "visigoda" (MERINO URRUTIA, 1977: 281).

Por otra parte, se había sugerido la idea de Bilibium como campamento romano merced a su proximidad para con las tribus cántabras (VILLACAMPA, 1980: 69s): hipótesis que hasta el momento no cuenta con fundamento arqueológico directo alguno.

Sin embargo, por las inmediaciones de Bilibio, incluso en su mismo término, sí se ha hecho discurrir el trazado de algunas calzadas antiguas, en algún caso calificadas sin duda como romanas, así como se han descubierto determinados restos arqueólogicos vinculados directamente a las mismas (la referencia de un miliario).

En efecto, con relación a las calzadas, además de la hipótesis de Sánchez Albornoz (1931: 23), sin confirmación arqueológica, de suponer una vía romana o ramal secundario del tramo Vindeleia-Deobriga que desde la Rioja cruzase los montes Obarenes por las Conchas de Haro, se han señalado más recientemente otros dos tramos de vías diferentes: 
de Buradón, Álava) ${ }^{11}$, separado de Bilibio únicamente por el Ebro en la cluse de las Conchas de Haro, con restos de la I Edad del Hierro (CAA: doc. 3517, pp. 250s), del poblado fortificado del Castillo de Portilla (Portilla, Álava), con materiales de la I y II Edad del Hierro (CAA: doc. 3501, pp. 242s), del poblado fortificado de La Ermita (Portilla, Álava) con vestigios arqueológicos de la II Edad del Hierro (CAA: doc. 3502 , pp. 243), del poblado fortificado de Valdeportilla (Ocio, Álava) con restos de la I Edad del Hierro (CAA: doc. 3526, pp. 253), del poblado fortificado del Castillo de Ocio (Ocio, Álava) con manufacturas de la I Edad del Hierro (CAA: doc. 3509, pp. 247) y del poblado fortificado del Portillo de la Casilla (San Román de Campezo, Álava) con evidencias de la I y II Edad del Hierro (CAA: doc.3511, pp.247s). A esta relación deben añadirse los hallazgos más recientes del Portillo de Lapoblación (Lapoblación, Navarra) y del término de El Tobal (Ocio, Álava).

- uno, el marcado gráficamente por Abásolo ( 1975, vid mapa) en el iter Ab Asturica Burdigalam entre las mansiones de Vindeleia (Cerro de Santa Cruz - Cubo de Bureba, Burgos; o más probablemente, La Llana de Silanes, Burgos - cf. ABÁSOLO, J.A., BARRIOCANAL, Y., RODRIGUEZ, J. 1982, pp. 167 - ) y Deobriga (Arce Mirapérez - Cabriana, Burgos / Álava) a la altura del paso de Pancorbo (Burgos) tras la inflexión al N. del derrotero aquitano para salvar los Obarenes: se trata de un ramal secundario que desde Pancorbo discurriría perpendicularmente al antoniniano en dirección E. para, entre Ircio (Burgos) y Miranda de Ebro (Burgos) y una vez traspasado el Ebro, entrar en territorio alavés por las inmediaciones de Zambrana. A este tramo se uniría a la altura de Bugedo (Burgos) el correspondiente a otra vía secundaria que en dirección S. a N. provendría de la mansión riojana de Libia ( Herramélluri) y que a juicio de Taracena (1942, pp. 38s) enlazaría esta zona berona con la vía aquitana ;

- otro, el propuesto por Martín Bueno y Moya Valgañón (1972) quienes basándose en documentación medieval aventuran la posible existencia de una calzada paralela al Ebro desde Miranda de Ebro hasta Vareia (Varea / Logroño) y en relación con la cual quizá pudiera estar el hallazgo de un supuesto tramo conservado de calzada romana - si bien no suficientemente justificado - en el mismo Bilibio (MERINO URRUTIA,1977: $281 \mathrm{ss})$. Tomando como referencia un texto de la Crónica de Alfonso III en el que se relata una de las incursiones de Alfonso I a mediados del siglo VIII en la Marca Superior, suponen la existencia de un camino antiguo por la orilla derecha del Ebro - derrotero que en 1096 vendría nominado como vía de Davaliellos - y del que "podemos presumir que esa vía seguiría aproximadamente el actual trazado de la carretera de Logroño - Miranda, por San Felices, al menos hasta Fuenmayor..." (MARTÍN BUENO, MOYA VALGAÑON, 1972: 168). La hipótesis fue recogida por Villacampa (1980: 79) quien además significó con relación a Castrum Bilibium: “...Esta ciudad posee interés por ser el núcleo de población más occidental del territorio berón dentro de la línea del río Ebro. En el confluían, berones, autrigones y várdulos. Su importancia de tipo estratégico se confirma por la supuesta ví que atravesaba dicha población y enlazaba Varea con el territorio autrigón.." (VILLACAMPA, 1980: 70). Esta denominada vía de Varea a Miranda de Ebro aparece incorporada, sin novedad significativa alguna para lo que se conoce, en el reciente repertorio sobre calzadas romanas de Álava, Navarra y la Rioja de De Miguel De Hermosa (1992: 359s).

Para finalizar, hemos de señalar la noticia dada por Prestamero (1792: 392), recogida también en el Diccionario Geográfico-Histórico de la Real Academia de la Historia (1802: 220), del hallazgo en 1781 de una columna miliaria, hoy día en paradero ignorado, perteneciente al emperador Póstumo, en Iricio, entre Bilibio y Miranda de Ebro - CIL II, 4919; BARÁIBAR, s.f. Ms. IRCIO; CORTA, 1928: 352; ELORZA, 1967: 145s, no 42; ABÁSOLO, 1975: 70s, 106s -, quizás en relación con el mismo trazado al que debe referirse el hallazgo de otro miliario de Póstumo en las cercanías de Vitoria, en Errekaleor (ABÁSOLO, LOZA, SÁENZ DE BURUAGA, 1983: 431s).

11. Sin pretender buscar aproximación tendenciosa alguna y únicamente con el objeto de marcar un fenómeno de aparente coincidencia etimológica es interesante recordar, en lo que respecta al topónimo Buradón, cómo, según escribió Marcial, los celtíberos del centro de la Península veneraban en el Burado (mons), próximo a Bílbilis, un encinar sagrado (SCHULTEN, 1959: 363s; BLÁZQUEZ, 1962: 9; id. 1975: 49; id. 1983: 289; CARO BAROJA, 1976: 166; TARACENA, 1982: 282;...); culto que ha sido puesto en duda por Marco Simón (1987: 63). 
En algunos de estos asentamientos indígenas se han descubierto en sucesivas prospecciones materiales arqueólogicos que atestiguan su romanización: son 1os casos del Castillo de Portilla, Las Ermitas, Castillo de Ocio y Portillo de Lapoblación.

Completaría este apartado relativo a la romanización el hallazgo de terra sigillata en las inmediaciones del alto del puerto de Herrera, en el monte San León, y Ias referencias epigráficas -además de las ya citadas de la ermita de San Bartolomé en Angostina - documentadas en Payueta (Álava) (Prestamero, L.Ms. sc. XVIII; BARÁIBAR, s.f., Ms. PAYUETA; ELORZA, 1967: 168, nº 96; VIVES, 1971: ILER 6783) y en la ermita de Nuestra Señora de Ocón (Bernedo, Álava) (SÁENZ DE BURUAGA, 1988: $543 \mathrm{~s}, \mathrm{n}^{\circ} 8$, foto 9$)^{12}$.

Conclusión derivada de todo ello -y al margen inicialmente de cualquier reducción con grupos étnicos concretos ${ }^{13}$ - es el notable repertorio de lugares con indicios y testimonios de ocupaciones indígenas a lo largo de la Edad del Hierro lato sensu que constituyen la prueba directa de un substrato de población precedente inmediatamente a la romanización.

Respecto a la antigüedad del nombre de Buradón hay que señalar que en un documento datado en el año 934 y recogido en el Cartulario de San Millán de la Cogolla ya aparece citado en sendas ocasiones como Buradon y Buradon Castro:

"...Alava, cum suis villis, ad suas alfoces pertinentibus, id est de Losa et de Buradon usque Eznate ferrunt: per omnes villas, inter domus decem una reia..." (UBIETO ARTETA, 1976, doc. 22, pp. 38).

Y en otro párrafo más adelante : "... Omnes villas de rivo de Alesanco et de rivo de Cardines, de vertice aque usque ad Naieram, et rivo de Tubia et Naiera, cum suis villis, et omnes ville de rivo de Eregua, Metrano, Bechera et Claviggo, et rivo de Leza, et rivo de Gubera, per horum rivorum omnes villas ex utraque parte aque, de vertice usque ad Iberum, et etiam de Buradon castro usque Sarta Acuta, omnes ville ex utraque parte aque Iberi, per omnes domus, singulas metitas de vino in oblatione et singulos panes in offerta...." (Op. cit. supra).

12. Los datos referentes al Potillo de Lapoblación, El Tobal y San León los debemos a su descubridor, Juan Antonio Madinabeitia, a quien agradecemos vívamente la deferencia

13. Tomando como base los datos aportados por la interpretación de algunos textos de la antiguiedad clásica - si bien puntuales y poco excesivos, pues "los Berones tiene poca mención entre las Regiones antiguas, por ser de corto ámbito. Ni Mela ni Plinio los expresan" (FLÓREZ, 1768: 168): se cuenta con referencias de Estrabón, Livio, Ptolomeo y del Itinerario de Antonino - se ha supuesto en un buen número de referencias escritas que la sierra de Cantabria/Toloño separaría a Berones meridionales de Várdulos septentrionales; indicadores lingüísticos y arqueológicos han sido utilizados para consolidar esta hipótesis -vid. al respecto, VILLACAMPA, 1980:.33ss, con bibliografía en notas 56 a 64- que sin duda ha pasado a ser prácticamente la única aceptada o manifestada - aunque la mayoría de los casos sin nuevos argumentos de peso y a modo de reafirmación con juicios, supuestamente concluyentes, ya establecidos - en la bibliografía general y local de la última docena de años: entre otros son significativos los casos de ALBERTOS, 1984 a: 267; EMBORUJO, 1985; GONZÁLEZ RODRÍGUEZ, 1986: 14; id. 1988: 148, BELTRÁN LLORÍS, 1987: 264; LLANOS, 1988 : 68; SANTOS YANGUAS, 1989: 27, 110; id. 1991: 207.

Como alternativa a esta hipótesis hay que entender la defendida por Taracena (1940: 160) -y compartida por Maluquer de Motes (1982, I, III: 29) - según la cual el río Ebro marcaría el límite septentrional de los Berones, de esta manera el territorio comprendido entre el cauce fluvial y la alineación de Cantabria / Toloño -es decir, el correspondiente en su integridad a la actual Rioja Alavesa- pasaría a ser competencia de Várdulos.

En cualquiera de los casos -volvemos a insistir- faltan hasta ahora elementos de juicio suficientes y significativos como para proceder a una reducción cualquiera: la investigación arqueológica en yacimientos pun- 
A juzgar por los datos que actualmente poseemos y en consonancia con el nivel de conocimientos al respecto, se puede avanzar la hipótesis de que, al márgen de otras manifestaciones selectivas, la romanización de esta zona se asienta en determinados casos sobre aquellos mismos lugares y, consecuentemente, pobladores indígenas. Indicadores arqueológicos y epigráficos pudieran avalar la tendencia propuesta.

\subsection{La Significación Cultural}

Es sobradamente conocido el hecho de que los pueblos antiguos y / o primitivos desarrollaron, entre otras prácticas arcaicas, formas de religiosidad naturalista, vinculadas a fenómenos y objetos propios de la naturaleza, y que, entre los variados elementos susceptibles de sacralización, los montes debieron contener los requisitos exigibles para con tal fin ( $c f$. ELIADE, 1983: 44ss; $i d .1985: 101 \mathrm{ss}$ ).

Un buen número de referencias escritas, literarias y epigráficas, de la antigüedad clásica traducen fórmulas cultuales de estas características concebidas como elementos de substrato o como estructuras propias de la religiosidad indígena. Manifestaciones que si bien parecen haber formado parte amplia del bagaje cultural de determinados grupos étnicos o lingüísticos -en términos generales, el caso de los celtas ha sido uno de los más aludidos (VENDRYÈS, 1948; LE ROUX, 1970)- no deben entenderse como productos exclusivos de los mismos (DE VRIES, 1963: 191s).

En nuestro caso, Marcial y Mela señalaban que la existencia de cultos a los montes entre los celtíberos del centro de la Península Ibérica y entre los pueblos de levante y noreste, dato este último ya recogido en la Ora Maritima de Avieno; Justino, por su parte, aludía a estas prácticas en las poblaciones del extremo nor- occidental de la Península: los teónimos Burado, Vadauero, (Mons) Caius, (Mons) Iouis, (Mons) Sacer e (Iugum) Zephyro, se han supuesto prueba de ello ( $c f$. SCHULTEN, 1959; BLÁZQUEZ, 1962; id. 1975; id. 1983; id. 1991; CARO BAROJA, 1976; TARACENA, 1982), lo cual no significa que queden exentos de problemas, pues, tal y como expresa Marco Simón (1987: 63s) para el caso concreto de la religión de los celtíberos, “...no contamos con evidencias que permitan afirmar la existencia de cultos a los montes, bosques o aguas en la religión de los celtíberos -o de los celtas, en general -. Lo que sucede es que la divinidad invisible se manifiesta a través de signos naturales, el trueno, la fuente, la cima de la montaña o el árbol..."14.

tuales de uno y otro lado de la cadena montañosa se hace necesaria a todas luces, máxime cuando las fuentes literarias de la antigüedad clásica se encuentran prácticamente agotadas y los datos aportados por la lingüística conlleven a un elevado número de limitaciones.

Mas si la cuestión es espinosa e irresoluble por el momento en esta parte del valle del Ebro - recuérdese además que como problema añadido habría que contemplar el corrimiento o desplazamiento espacial de los grupos étnicos a lo largo de la antigüedad ( $c f$. DUPRÉ, 1973) -, mayores dificultades conllevaría todavía el intentar discernir la posición del castro Bilibio pues a la competencia de los dos grupos étnicos habría que incorporar la de unos terceros Autrigones - a propósito de los límites de éstos, vid. SOLANA SÁINZ, 1974 y prólogo de la obra por MONTENEGRO DUQUE, pp. 6 s; id. 1978-.

14. A propósito de la religiosidad de los celtíberos, además del estudio referido de Marco Simón, entre las aportaciones más recientes hay que significar la síntesis de Sopeña (1987) y los trabajos de Salinas de Frías $(1982 ; 1985)$. 
Aceptando, pues, la relatividad de los datos $-\mathrm{y}$ sobre todo las precauciones derivadas de sus interpretaciones o proyecciones - y volviendo a tomar la cuestión inicial, en el contexto septentrional peninsular se conocen referencias epigráficas puntuales entre galaicos (Larocu, y menos precisadas: Iupiter Ladicus, Iupizer Candiedo), astures augustales (Tilleno, Marti Tilleno) -menor seguridad se tiene para los astures transmontanos (Ioui Candamio) - y berones (Dercetio), caso éste sobre el que posteriormente volveremos ( $c f$. ALBERTOS, 1974) $)^{15}$.

De los testimonios hasta ahora vistos se deduce el hecho de que, junto a teónimos propios vinculados a montes precisos (Larocu, Tilleno, Dercetio), existe otra serie que parece asimilar el culto con Júpiter y Marte a modo de sincretismo religioso ${ }^{16}$.

Mas, es sin duda el marco del Pirineo, especialmente en su tramo septentrional central, y región aquitana quien mayor número de teónimos vinculables con el culto a los montes ha aportado merced a la documentación epigráfica disponible: sirvan a modo de ejemplo, además de las referencias más claras a (Diis ) Montibus, a Sex Arbori (deo), o a Fagus, los casos, tradicionalmente más aceptados, de Ageioni, Bascei, Bassiario, Erge ó Garre/i, ofreciendo mayores dificultades los de Arhe, Arixoni, Arpenino, Borienno, ó Ele (cf. en especial, SACAZE, 1885; id. 1892; y más recientemente, GORROCHATEGUI, 1984) ${ }^{17}$.

15. Si bien correspondiente a un territorio más meridional, propio en la antigüedad de los Vettones, no hace muchos años Albertos identificaba al dios cacereño Salamati (dat.) -tradicionalmente vinculado desde su conocimiento en la bibliografía impresa (RUBIO ALIJA, 1955: 298) con una divinidad fluvial asimilable al río Tormes y relacionable por su supuesta lectura como Salama( n)ti con Salmantica / *Salamantica (TOVAR, 1955: 114s) - con la montaña de Sálama / Jálama, en el límite actual entre Salamanca, Cáceres y Portugal (ALBERTOS, 1985 b: 469s).

Sobre referencias epigráficas a esta divinidad y acerca del culto a Sálama, vid. MELENA, 1985.

Precisamente en esa misma área parece tener una función similar a Sálama el teónimo indígena Eaecus, estrechamente vinculado a Iuppiter Salutorius y con quien debió encontrarse asimilado en un mismo culto sincrético (SALINAS DE FRÍAS, 1982: 333; id. 1985: 323ss; id. 1986: 77; SALAS, REDONDO, SÁNCHEZ, 1983: 243 ss; MELENA, 1985: 484).

16. En este sentido, si bien centrado en el paradigma del Noroeste peninsular, se ha llegado a suponer la existencia paralela de dos tipos de cultos de montaña: uno indígena y de origen pre-romano, vinculable al segundo eslabón del esquema tripartito de la mitología indoeuropea como estableciera Dumézil (1958), asimilado con Marte, de ahí su carácter guerrero, como deidad de la montaña (cf. Marti Tilleno), y otro implantado por Roma en el que, al igual que la mitología griega asociaba las cimas de los montes con la figura de Zeus, el dios de la montaña en Júpiter y cuyo culto "está intimamente unido a la figura del emperador y sirve como medio de cohesión social entre las fuerzas indigenas y las romanas" (PENAS TRUQUE, 1986: 140).

Sobre cultos a los montes entre los galaicos, vid. RODRÍGUEZ COLMENERO, LOURENCO FONTES, 1980.

17. Escribía Sacaze: “... Strabon a constaté les différences qui existaient entre les Aquitains et les habitants des autres parties de la Gaule, différences si profondes quant au langage et à la constitution corporelle, qu'au dire du géographe grec, les Aquitains ressemblaient plus aux Ibères( d'Espagne) qu'aux Galois... Les Aquitains avaient aussi leurs divinités propres, absolutement disticntes des divinités celtiques et romaines, et c'est là le trait véritablement caractéristique de l'épigraphie religieuse des pyrénéens... L'importation des divinités étrangères paraît s'être effectuée sans lutte et, même, sans protestation... D'ailleurs, nos ancêtres pyrénées... ne se préoccupaient guere, j'imagine, de ce mélange de divinités et de doctrines, source d'un syncrétisme religieux fort compliqué... Au fond, leurs croyances restaient les mêmes, et, quels que fussent les noms des divinités locales ou étrangères inscrits sur les autels votifs, c'est à la Nature surtout que s'adres- 
Por su parte, Barandiarán (1960: 62), descubridor de la mitología vasca, ya constató el hecho de que las montañas en variados espacios y a lo a largo del tiempo llamaron la atención de las gentes de muy diversas maneras, sugiriendo, en determinados casos y merced a su singular aspecto, dentro de la imaginación popular, proyecciones de figuras, personajes u objetos concretos. Con todo ello, esas tendencias animistas han generado la existencia de fantásticas leyendas en torno a ellas: en el País Vasco un buen número de peñas (Amboto, Aralar, Aya, Gorbea, Oiz, Orduña, Orhy,...) " son objeto de creencias y leyendas de antigüedad remota, reliquias de su pasado, ruinas de arcaica religión, desfiguradas tal vez por influencias de cultos posteriores..." (BARANDIARÁN, 1960: 108). Mari, numen por excelencia de la mitología vasca, de indudable carácter ctónico, es una figura asociada directamente a las montañas: abundarían en ello las denominaciones que recibe (BARANDIARÁN, 1928; CARO BAROJA, 1980).

Ciñéndonos al contexto más inmediato de Baelibio/ Bilibio encontramos dos nuevas referencias que por extensión avalarían la hipótesis de la sacralización de la montaña.

En las inmediaciones de Bilibio y formando parte de la misma cadena montañosa existe una notable peña llamada Toloño (1267 m.) que, merced sin duda a su amplitud y majestuosidad, ha dado nombre a una importante parte de la sierra anteriormente aludida de Cantabria/ Toloño (fig.5).

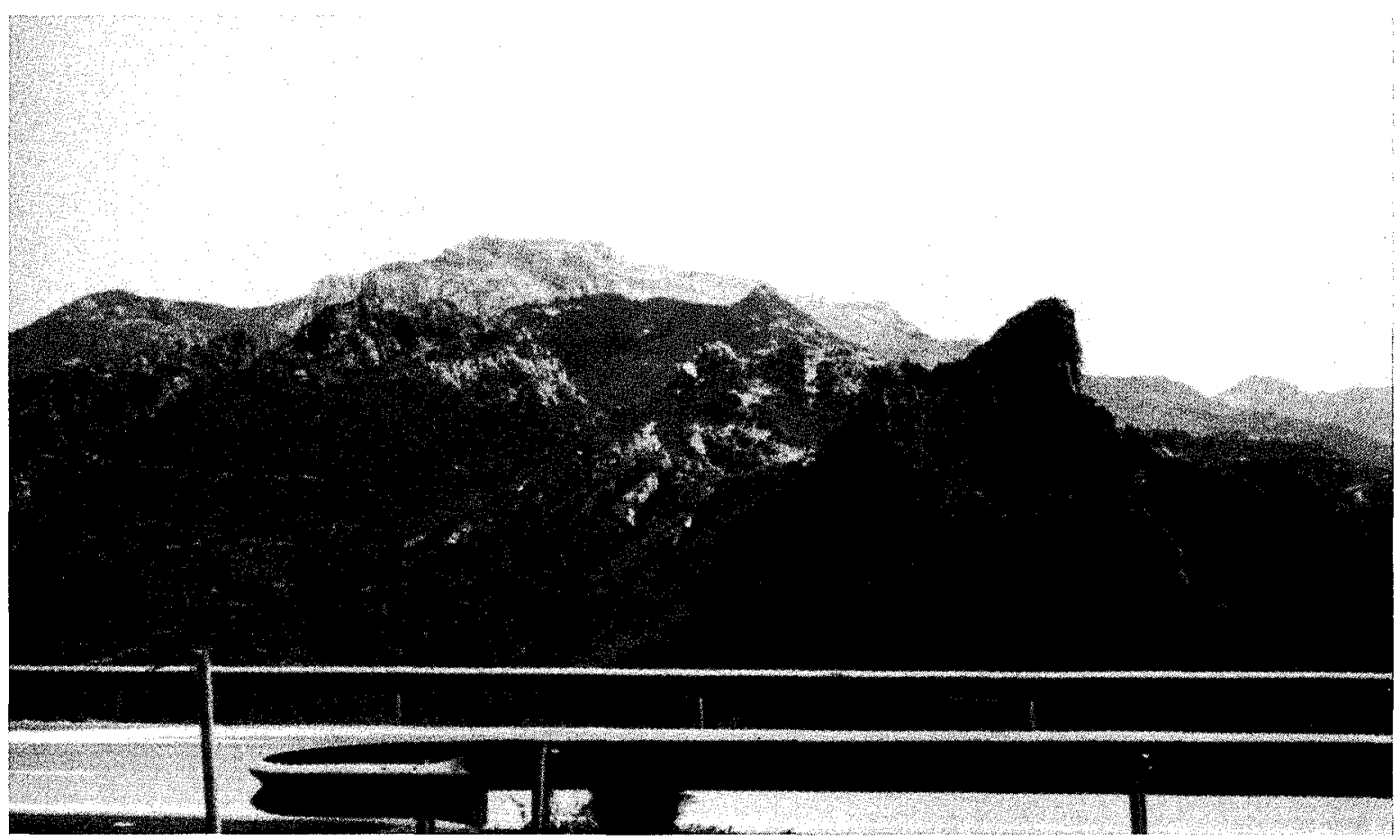

Panorámica desde Bilibio: en frente Buradón, al fondo Toloño.

El 12 de Septiembre de 1799 el erudito alavés, Prestamero reconoció en las inmediaciones del Castillo de Henayo (Dulantzi, Alegría de Álava), aproximadamente a unos 33 kms. en línea recta al N.- NE. de la referida peña de Toloño, un fragmento de lápida votiva, perdida actualmente, ofrecida al dios Tullonio (dat.) (CIL II, 2939) (fig.6 ver pag. siguiente). A pesar de haberse encontrado en ese sitio de la Llanada Alavesa, al que se ha venido identificando tradicionalmente con una de las mansiones -la de Tullonio- citadas a lo largo del iter Ab Asturica Burdigalam en el Itinerario de Antonino y que según las 
noticias de Ptolomeo habría que hacer corresponder con la ciudad várdula de Tullonium, Albertos (1974: 155-157) vincula a la divinidad con el Monte Toloño ${ }^{18}$ ( fig.7).

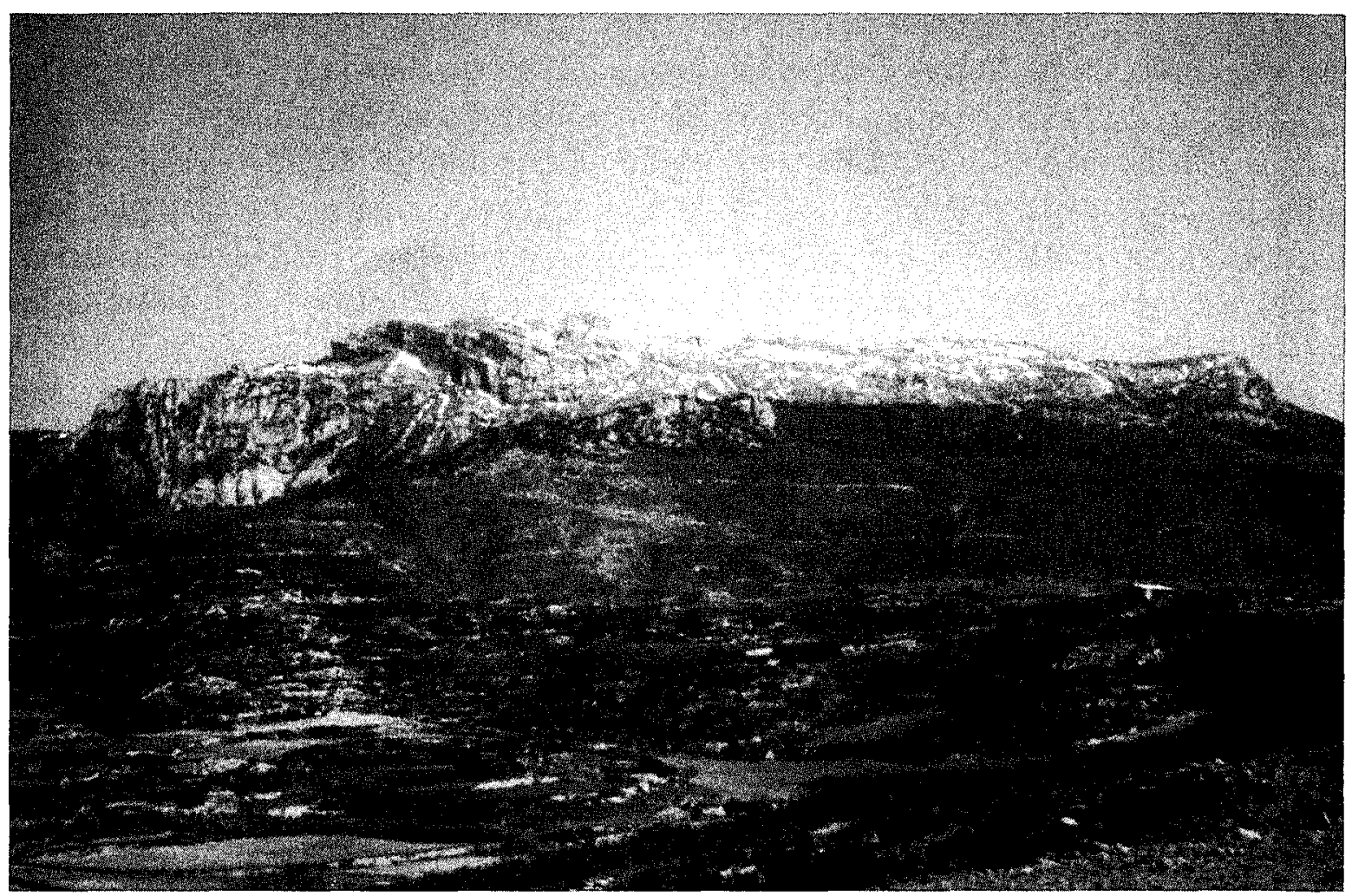

Flanco meridional de Toloño

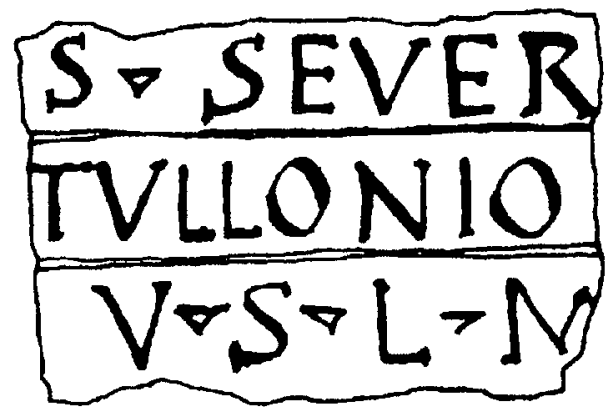

Inscripción a Tullonio (copia del manuscrito de F. Baráibar).

saient leurs hommages; ils adoraient les Sources, les Arbres, les Forêts, les Montagnes, le Feu, les Pierres, etc. Même de nos jours, les antiques superstitions ne sont pas encore complétement déracinées, et l'on peut retrover, dans les hautes vallées, les traces et, parfois, les manifestations de l'ancien culte, si profondément naturaliste..." (SACAZE, 1985: 3s).

A propósito de prácticas supersticiosas arcaicas en los pueblos de la Península Ibérica, vid. MENÉNDEZ PIDAL, 1965, I: 285ss.)

18. La identificación del teónimo Tullonio con el culto al monte Toloño propuesta por Albertos, a quien siguen Solovera y Garabito (1978: 153s), no ha sido la única al respecto. Prueba de ello constituyen las hipótesis de Prestamero (1792: 309) que consideraba a Tullonio no como deidad sino como lugar en el que se cumplió el voto; de Hübner (CIL II, 2939) que lo interpretaba como nombre de una divinidad ; de Baráibar (Ms. Alegría) que lo señaló como " patrón, sin duda, de la población del mismo nombre, citada en el Itinerario de Antonino y en las Tablas de Ptolomeo", criterio con el que coincidiría Toutain (1967: 156) al hablar de él como divinidad protectora o genio municipal, es decir, como "dieu de la ville de Tullonium"; de Fernández Guerra (1883: 26) 
Desde Bilibio y Toloño es fácilmente divisable, a mediodía, en tierras beronas de la Cordillera Ibérica, la sierra de la Demanda y en especial su mayor cota, el pico San Lorenzo (2262 m.). Siguiendo a Albertos (1974: 153-155), en 1864 se encontró en el municipio riojano de San Andrés, en las proximidades de Berceo y San Millán de la Cogolla, un ara, conservada actualmente en el Monasterio de San Millán de Yuso, de la que únicamente era y es claramente legible el teónimo inicial de Dercetio (dat.) (CIL II, suppl., 5809; ESPINOSA, 1986: 59s, nº 40, lám. 5) (fig.8). Por su parte, San Braulio, al escribir la vida de San Millán, menciona como lugar de retiro del santo el Dircetii montis, conservándose el nombre como adjetivo Dercensis del Monasterio de San Millán hasta principios del siglo XI -el año 946 firmaba el abad de San Millán Gomesani Abbat. Sancto Emiliano Dircecii Monasterii regenti y en escritura de Albelda del año 950 firma Stephanus Dercensis Abbas de Sancto Emiliano (Miguella,1919: 15) - en que pasa a ser conocido como Vergegio ${ }^{19}$ y de aquí Berceo.

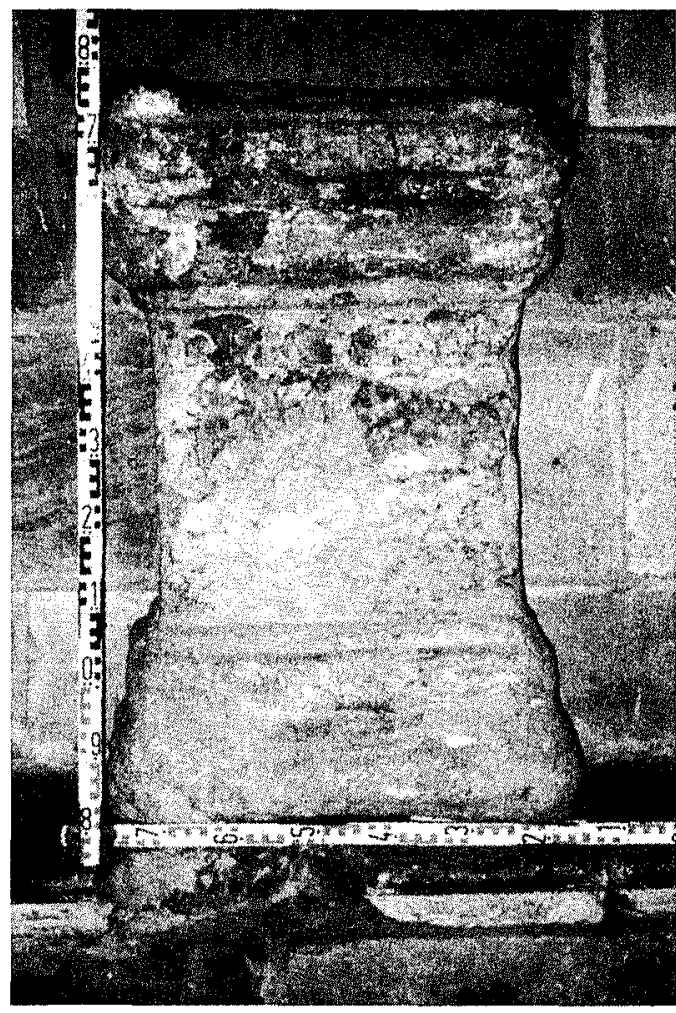

Ara de Dercetio en el Monasterio de San Millán de Yuso.

quien convenía "en que era nombre de una deidad ibérica, de un semidiós, de un monte, de una fuete salutifera, y que tuvo quizá su principal santuario en la sierra de Toloño"; de Blázquez (1962: 85; id. 1983: 289 s) que lo menciona como dios cuyo nombre es un topnímico alusivo a la situación geográfica del centro de su culto: la mansión de Tullonium; o, de la misma Albertos (1970: 161s) quien inicialmente, además de catalogarlo como divinidad pre-romana, identificada con el toponímico Tullonium, sugería también una posible relación con la sierra de Toloño, hipótesis de la que se harían eco Elorza (1972: 365) y Blázquez (1975: 176).

19. El toponímico Vergegio aparece vinculado a un núcleo de población ya en la Vita Sancti Aemiliani escrita en torno al siglo VII por San Braulio -uilla Vergegio, eclessia Vergegio (VÁZQUEZ DE PARGA, 1943, 10, 12: 15, 16 )- de donde cabe suponer su existencia ya a fines del siglo V. Por otra parte, siguiendo a T. Minguella, el epígrafe funerario de San Millán hace originario de este lugar-oppido Vergegii-al santo eremita (citado por VILLACAMPA, 1980: 132). 
Con todo ello, Albertos no duda en vincular el teónimo con algún monte próximo de la sierra de la Demanda, sugiriendo que, de atender al significado de la etimología indoeuropea del radical -*derk, "ver, mirar" de ahí "el visible”, pudiera quizás identificarse con el pico San Lorenzo ${ }^{20}$.

A modo de balance de lo hasta ahora expuesto hemos de concluir diciendo, por una parte que el teónimo Baelibio debe identificarse con una divinidad de la montaña que ha pervivido en el toponímico del, no muy lejano, monte Bilibio, y, por otra parte, que en ese mismo contexto espacial ( e inmediaciones) existen además otras referencias complementarias que traducen ese fenómeno de la sacralización de los montes como manifestación externa de la religiosidad de los pobladores indígenas del entorno ${ }^{21}$.

\section{Apuntes Complementarios}

No queremos finalizar este puntual artículo sin dejar de llamar la atención, aunque sea brevemente, acerca de algunas manifestaciones que competen a la antigua

Si en el siglo XI se asocia este nombre al Monasterio de San Millán, hacia 1180 era con el de Cuculla, préstamo sin duda del pico San Lorenzo que en 1199 aparece nominado como San Llorent de Cuculla (MINGUELLA, T. 1919, pp.15), de donde fácilmente evolucionaría a la forma Cogulla -grafía bien conocida en el siglo XIX (cf. San Millán de la Cogulla: GOVANTES, 1846: 162 )- y de aquí al actual Cogolla.

20. Toutain llegó a plantear la posibilidad de un mismo culto a Dercetius en el texto de San Braulio: “...Il faut peut-être voir une allusion au culte de Dercetius dans le détail siuvant: "Quas ibi ille invisibiles quasque pugnas visibiles, quas vario collidoque modo tentationes, quesque nebulonis antiquissimi hedificationes fuerit expertus..". Cet ANTIQUISSIMUS NEBULO ne serait-il précisément Dercetius, le démon de la montagne?..." (TOUTAIN, 1967: 145, nota 2).

21. La constatación de cultos a los montes en la alineación montañosa de Cantabria / Toloño por parte de pobladores indígenas conduce a una reflexión acerca de la significación de determinados y pretendidos grupos étnicos y de su ubicación en el espacio.

Ya se ha apuntado cómo la cuestión en términos generales de los límites en esta zona entre Várdulos y Berones es muy problemática y cómo ésta se acrecienta en el extremo occidental de la misma por la presencia de los Autrigones en las inmediaciones de Bilibio (vid. nota 13).

a) Partiendo de la inestabilidad de los límites, parece claro que desde cualquiera de las dos hipótesis lanzadas al respecto - la identificada con Cantabria / Toloño como límite y la que hace lo propio con el Ebro hay cuasi uniformidad en adscribir la mayor parte del territorio ubicado en las estribaciones septentrionales de Cantabria y Toloño al denominado grupo étnico de los Várdulos.

b) Se acepta tradicionalmente que la mansión de Tullonium, citada por Ptolomeo y en el Itinerarium Prouinciarum Antonini Augusti como ciudad várdula, debe situarse en las inmediaciones del lugar de aparición del epígrafe dedicado a Tullonio: el castro del Castillo de Henayo (Dulantzi, Alegría de Alava).

c) Tomando como válida la vinculación del teónimo Tullonio con el orónimo Toloño pudiera convenirse que, en cierta manera y durante algún tiempo, este monte, en el mismo límite de la inestabilidad entre Várdulos y Berones, pudiera haber formado parte del patrimonio espacio-cultural de los Várdulos.

d) Teniendo en cuenta la ubicación de Bilibio en la misma alineación montañosa que Toloño, su inmediata cercanía para con él - poco más de siete kilómetros separan ambas cumbres -, la relativa coincidencia material inicial, que no temporal, en el registro arqueológico con el castro de Buradón, en la otra orilla del Ebro - por lo que quizás éste no debía suponer un obstáculo infranqueable -, además de la coincidencia significativa con Tullonio en lo relativo a una práctica cultual vinculada a la sacralización de los montes y docu- 
cristianización de la zona y que, al menos en apariencia formal, parecen descansar o solaparse sobre objetos de culto pagano tales como los hasta ahora expuestos. Nos referimos concretamente al fenómeno de los eremitorios.

Conocemos por San Braulio cómo San Millán -se calcula por su larga vida de ciento un años y muerte en el 574 que nacería hacia el año 473, en las proximidades de Vergegio (Barceo, La Rioja) - a los veinte años de edad se sintió atraído por la fama del eremita Felices que habitaba en los riscos de Bilibio (fig.9) -"...dictauerat ei fama esse quendam heremitam nomine Felicem, uirum sanctissimum cui se non immerito praeberet discipulum, qui tunc morabatur in castellum Bilibium..." (VÁZQUEZ DE PARGA, 1943: 14; LYNCH, GALINDO 1950: 268, nota 57)- y cómo una vez instruido en su doctrina volvió a su aldea natal donde deseoso de llevar vida solitaria se retiró a lo más apartado del monte Dircetio, habitando en su seno cuarenta años como eremita -"...remeat ad sua, doctrinae gratia copiosus; ac sic uenit haud procul a uilla Vergegio, ubi nunc eius habetur corpusculum gloriosum, ibique non multo moratus tempore uidet inpedimento sibi fore hominum ad se concurrentium multitudinem. Celsiora petit,... peruenit ad remotiora Dircetii montis secreta..., quadragenis ibi fere habitans recursibus..." (VAZQUEZ DE PARGA, L. 1943, 10, 11, pp. 15 s; LYNCH, C.H., GALINDO, P. 1950, pp. 268, nota 58)-. Tras ejercer durante algunos años, por orden del obispo Dídimo de Tarazona, como presbítero de la iglesia de su natal Vergegio, volvería definitivamente a su antigua morada de la montaña -que Fray J. Pérez de Urbel (1934, I, pp. 172ss) identifica con el mismo monte Dercetio, de ahí que el Monasterio de San Millán lo conservase como adjetivo hasta el siglo XI- donde en compañía de otros clérigos- se han citado a

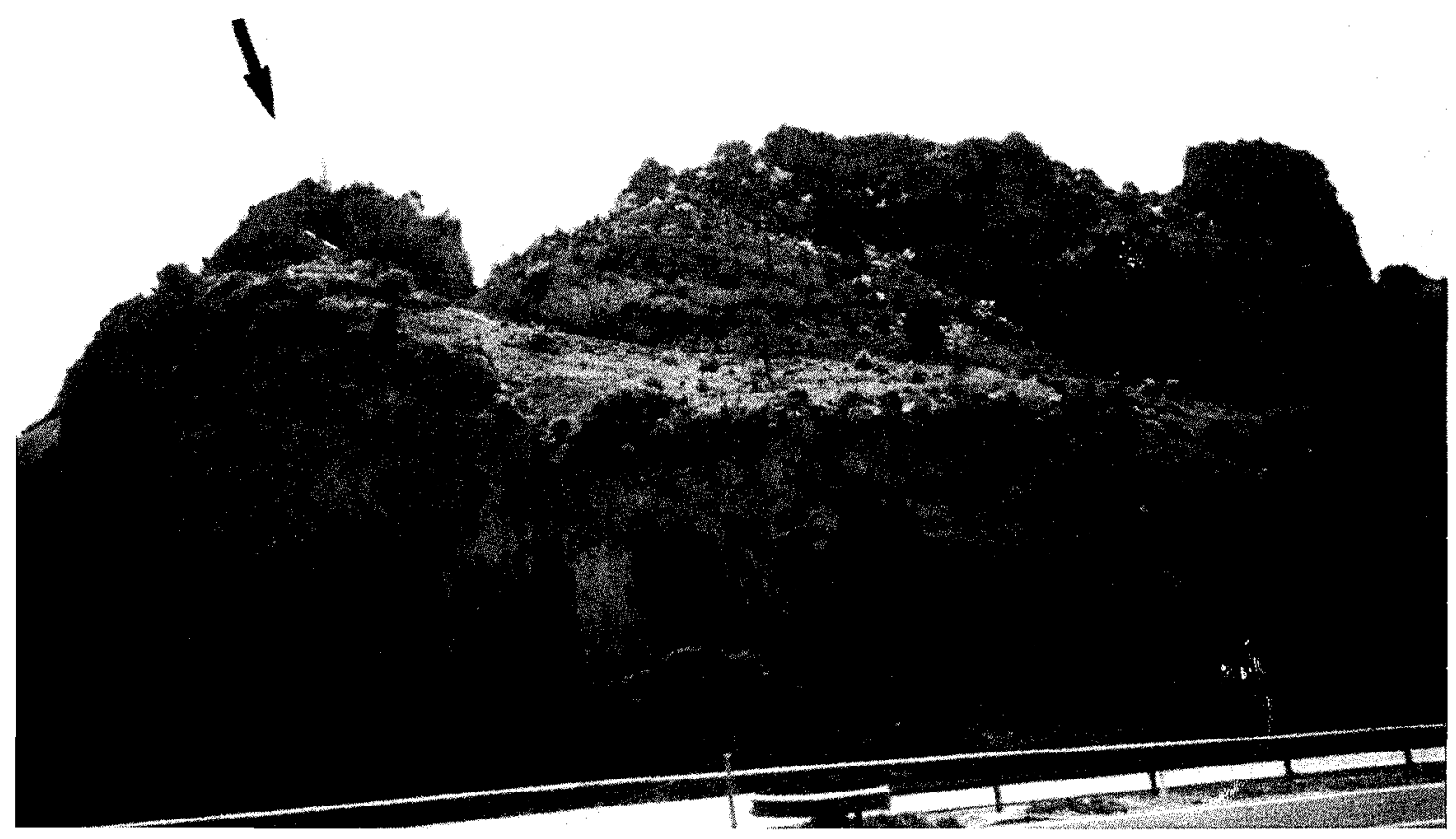

Ermita de San Felices en los riscos de Bilibio. 
Aselo, Citonato, Geroncio, Sofronio y Potamia- construyeron el cenobio sobre el que actualmente se halla el Monasterio de San Millán de Suso (fig.10) -edificio de puj ante existencia hasta mediados del siglo XI cuando por problemas de espacio se erige uno nuevo, el actual Monasterio de San Millán de Yuso, en la parte baja del valle y al que serían trasladados del anterior las reliquias del santo eremita-.

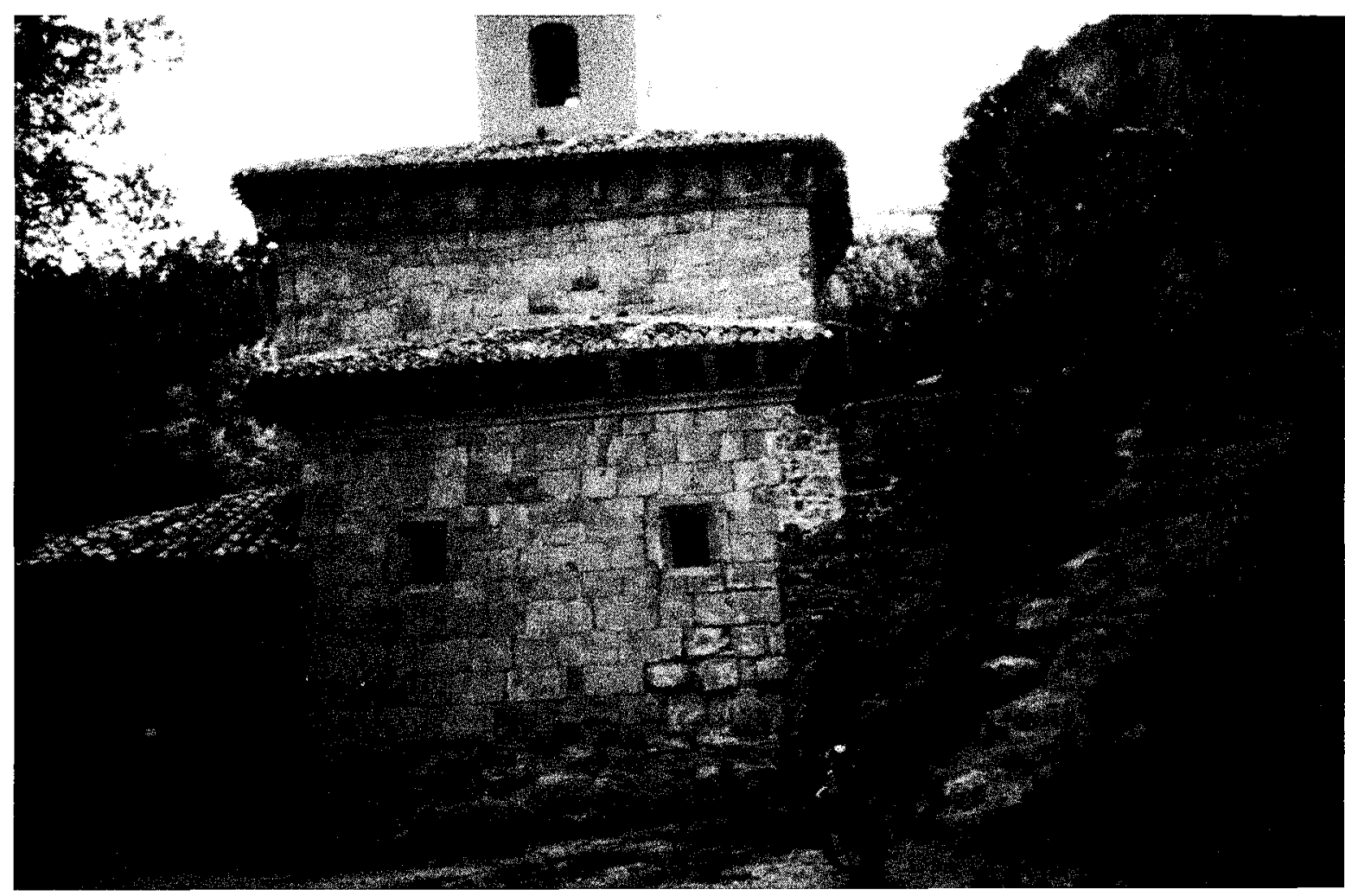

Monasterio de San Millán de Suso.

Así pues, merced a los textos escritos y a otros repertorios de la cultura material, se deduce en este caso cómo a la antigua estructura de religiosidad indígena de Dercetio se supraponen manifestaciones cultuales de la antigua cristianización (eremitorios) que progresivamente darán lugar a otras producciones más evolucionadas (Monasterios de San Millán de Suso y de San Millán de Yuso).

En el mismo contexto de la Demanda se conocen temas paralelos al documentado de San Millán. Quizás el caso más significativo sea el de Valvanera (La Rioja). Con anterioridad a la erección del Monasterio benedictino de Santa María de Valvanera a fines del siglo $\mathrm{X}$, parece ser que la zona debió poseer una amplia tradición eremítica "que confirió al lugar de enclave el título de Tebaida, nombre al que la tradición local enlaza el recuerdo de la visita de San Atanasio" (ALDEA VAQUERO, MARÍN MARTÍNEZ, VIVES GATELL, 1972, III: 1694s). En Valvanera además se asiste a un primitivo culto pagano -el de los árboles y concretamente el roble ( $c f$. ELIADE, 1981: 274-334; id. 1985: 127ss; FRAZER, 1981; para la Península Ibérica, vid. CARO BAROJA, 1950; id. 1974: 339-351)-que la tradición cristiana vinculó con el culto a la virgen: MINGUELLA, 1919: 92ss) recoge una leyenda en la que allá por el siglo IX un ángel ordenó a Nuño Oñez -hombre arre- 
pentido de su vida licenciosa que cumplía retiro como eremita en la roca de Tresvalles (Trómbalos), cerca de Anguiano- a que fuera a Valvanera a recuperar la imagen de la virgen dentro de un roble -imagen que la misma tradición suponía ocultada en época de la invasión árabe o goda, lo que en consecuencia hablaba de un culto anterior (VALDIVIESO, 1986: 222)-. Como ya ocurriera con el pico San Lorenzo o con el antiguo cenobio de San Millán, se ha identificado el lugar en el que se encuentra ubicado el santuario de Valvanera con el monte Dercetio -Minguella (1919: 13) se ampara para proceder a tal reducción en el hecho de que en un diploma de Alfonso VI del año 1092 se menciona al sitio en que se fundó el monasterio como Distercio-, de tal suerte que Valvanera vendría a ser la manifestación cristiana de un antiguo culto indígena vinculado con el roble y con la montaña (VALDIVIESO, 1986: 229ss).

No menos interesante que los precedentes se ofrece el caso de Bilibio. A la ya conocida morada y primitivo sepulcro de San Felices en la cumbre de Bilibio -por la Vida de San Millán que redactara San Braulio se estipula que Felices pudo nacer hacia el año 443 y que habiendo tenido una longevidad en años parecida a la de su discípulo Millán fue enterrado tras su muerte, en torno a la mitad del siglo VI, en el eremitorio de la cumbre de Bilibio donde permaneció hasta el año 1090 en el que sus restos fueron trasladados al Monasterio de San Millán - hay que añadir el complejo de eremitorios ubicados en sus estribaciones nor-occidentales, a pocos metros del Monasterio de Nuestra Señora de la Herrera, edificio cisterciense del siglo XII ${ }^{22}$, ya en tierras burgalesas de Miranda de Ebro. Este conjunto eremítico de la Herrera enlazaría con el denominado de La Onza, al sur de Bilibio y en el camino antiguo de Haro a Villalba de Rioja, y más a occidente con el de Peña Escalera, próximo ya al existente en La Morcuera, cerca de Miranda de Ebro, y sobre el que se fundó a fines del siglo XIV el Monasterio de San Miguel del Monte, de la orden de San Jerónimo.

Por lo que respecta a Toloño, "a juzgar por lo que nos dice el P.Sigüenza, historiador de la orden de San Jerónimo, era al principio una ermita junto a la cual vivían algunos ermitaños dedicados a la vida espiritual y penitente en lo más alto de la cumbre..." (CANTERA OLIVE, 1967: 200). Posteriormente, por bula de Benedicto XIII, se construyó allí mismo el Monasterio de Santa María de Toloño, con ulterior advocación de Nuestra Señora de los Ángeles, que desde fines del siglo XIV y hasta su abandono en 1422 estuvo bajo la regla de San Jerónimo y agregado al de San Miguel del Monte (ARMENTIA, 1968: 26s). Si hasta el presente no se ha llegado a verificar la existencia de eremitorio alguno en la cima de Toloño, no ocurre lo mismo en sus estribaciones inmediatas: prueba de

mentada en sendos textos epigráficos, si bien fuera de contexto, hallados en territorio várdulo, pudiera plantearse a modo de interrogante - lógicamente a la espera de ulteriores datos y únicamente, insistimos de acuerdo con el enunciado, como reflexión puntual - que quizás no sería excesivamente descabellado pensar en una conexión del sitio de Bilibio, tradicionalmente vinculado al territorio berón, con el denominado grupo étnico de los Várdulos.

22. Los orígenes de este monasterio hay que buscarlos a principios del siglo XII como hospital vinculado a la ruta jacobea. Fundado inicialmente por monjes cluniacienses, Alfonso VIII donaría hacia 1176 el edificio a la orden del Cister. A partir de este momento el monasterio de bernardos de la Herrera tendría vida próspera hasta principios del siglo XIX. Tras un abandono parcial (1808-1814) a causa de la Guerra de la Independencia continuaría su labor hasta 1835 en que la Desamortización lo confió a manos de particulares. Posteriormente, en 1896, sería ocupado por religiosos carmelitas quienes en 1905 lo vendieron a una comunidad de monjas trapenses. A partir de 1923 y hasta la actualidad el edificio está ocupado por eremitas camal- 
ello constituirían, por su parte meridional, el conjunto eremítico de Peña del Trillo/La Lobera y San Juan (Labastida, Álava) y, por la septentrional, escalonadamente, los de la Cueva del Molino (Ocio, Álava) (fig.11), la denominada Choza del Fraile (Berganzo, Álava) y los emplazados en el travertino de Herrerías (Payueta, Álava) (fig.12).

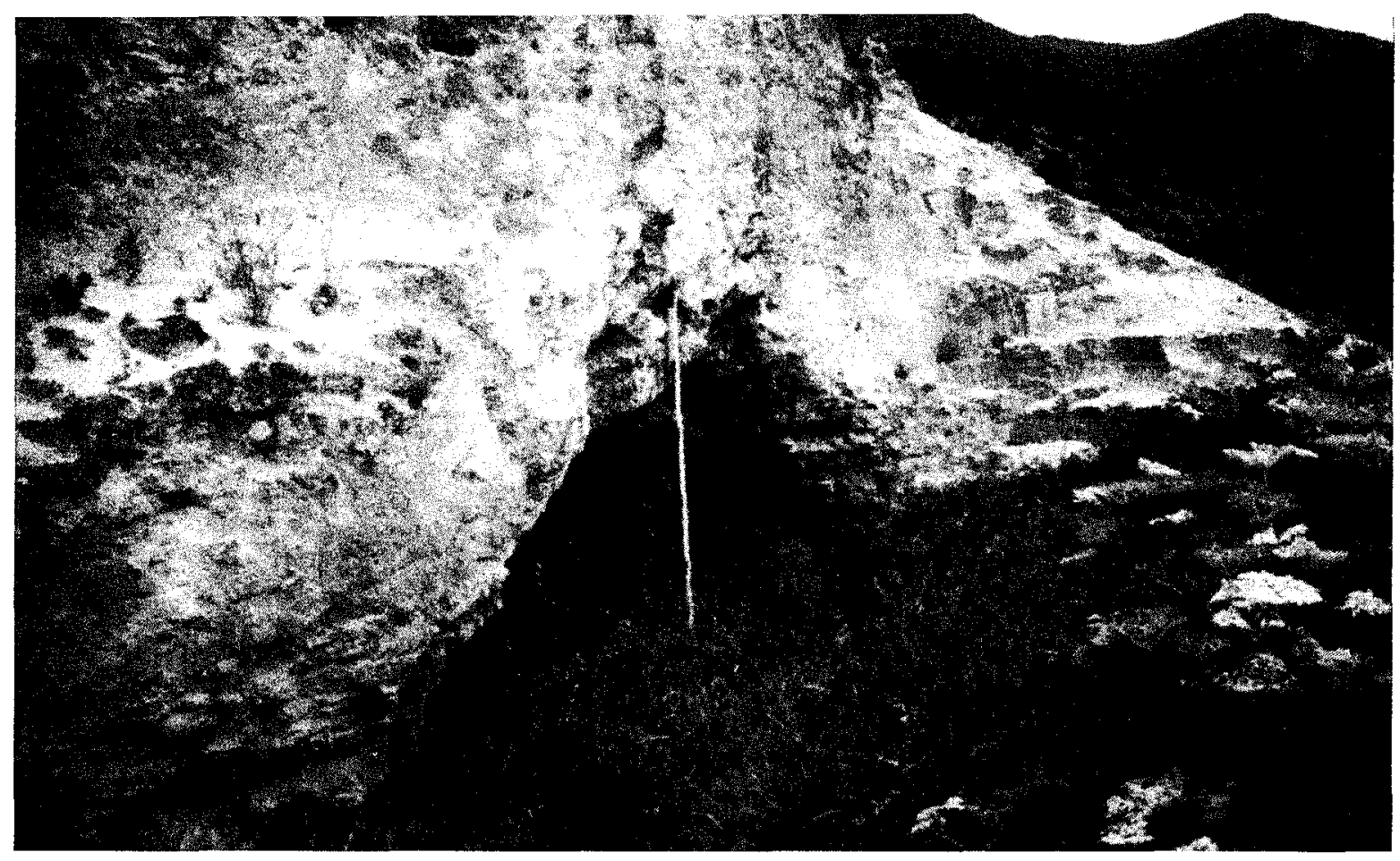

Eremitorio sobre travertino de la Cueva del Molino (Ocio, Alava).

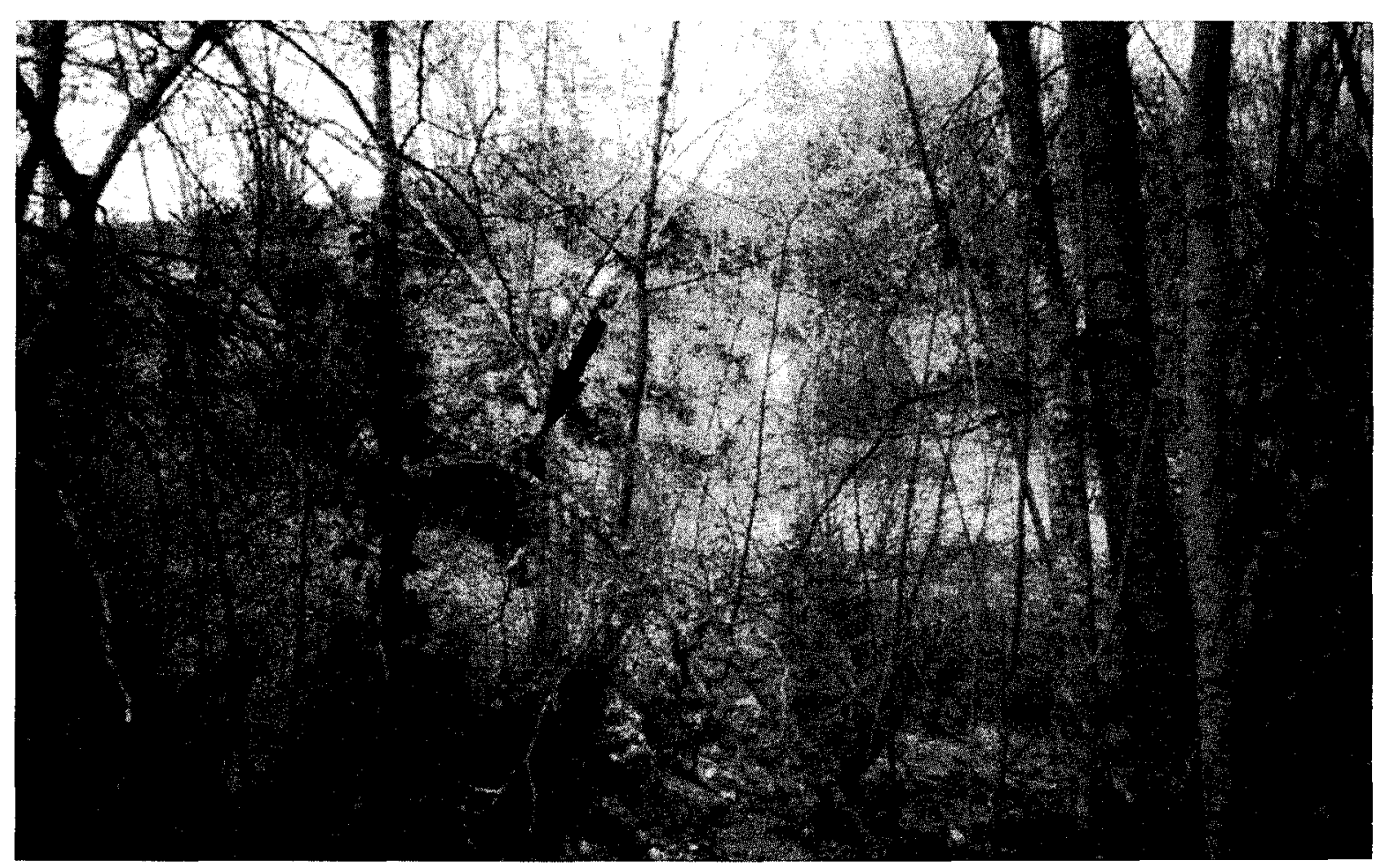

Eremitorio sobre travertino de Herrerías (Payueta, Álava). 
De esta forma, en los casos expuestos tienden a repetirse una serie de constantes que, al margen de una cronología precisa para cada cual, constituyen manifestaciones formales de una progresiva religiosidad y que, desde una perspectiva más inmediata, quizás puedan explicarse, aun aceptando causalidades diferenciales en los hechos, como exponentes en cierta medida de la antigua cristianización de lugares o referentes paganos ${ }^{23}$.

Por último, la existencia de estos eremitorios no debe entenderse como un fenómeno puntual en ese espacio físico sino como parte integrante de otro más amplio que transciende sobradamente nuestras coordenadas espaciales de referencia: los casos de Peña Amaya (Burgos) y Herrera de Pisuerga (Palencia) pueden obrar como testimonio al respecto.

En nuestra más inmediata realidad concluiríamos diciendo que el fenómeno enlazaría, desde la parte más oriental, la red de eremitorios de la zona de Oña (Burgos), a través de los existentes en el paso de Pancorbo / Ameyugo (Burgos), con los que venimos de señalar en los Obarenes -al caso de Bilibio e inmediaciones habría que incorporar los existentes en el denominado Museo del Vino (Briñas, La Rioja) y proximidades de Haro- y, una vez salvado el Ebro, con los igualmente apuntados en las estribaciones de Toloño, para, siguiendo el corredor del Inglares y a través de Berganzo y Payueta, empalmar e su parte más oriental con los bien conocidos alaveses de Baroja, Faido, Laño, Urarte y Marquínez ${ }^{24 y 25}$

dulenses vinculados a la Congregación de Monte Corona (Italia) que establecieron en él su primer, y hasta ahora único, yermo en el Estado español (ALDEA VAQUERO, MARTÍN MARTÍNEZ, VIVES GATELL, 1972, III: 1574s) : se trata ésta de una orden peculiar que, fundada en Italia a fines del siglo X o comienzos del XI por San Romualdo, intentó refundir el ideal eremítico oriental y el cenobítico occidental (Op. cit. supra, I: 332).

23. Complementariamente con ello, se ha supuesto que la hagiotoponimia de alguna de estas comarcas concretamente, la documentada a uno y otro lado de la sierra de Cantabria / Toloño - pueda quizá ser exponente del arraigo del cristianismo en épocas altomedievales: las advocaciones de un buen número de templos y ermitas pueden traducir cultos hispano-visigodos y mozárabes (GARCÍA FERNÁNDEZ, LÓPEZ LÓPEZ DE ULLÍBARRI, DÍAZ DE DURANA, 1990: 26s).

Acerca de la cristianización en el País Vasco y de su problemática derivada, vid. la reciente aportación de Larrañaga y Azkarate (1988).

24. Una visión precisa y reciente del proceso de investigación y de la documentación bibliográfica relativa al tema de los eremitorios alaveses se halla recopilada en la monografía de Azkarate (1988: 136ss). (1989).

Para las últimas aportaciones sobre el tema, vid., además de la obra de Azkarate, la síntesis de Monreal

25. Agradecemos a Pepe Elejalde el habernos confiado desinteresadamente los datos relativos a sus descubrimientos de los complejos de Oca, Pancorbo / Ameyugo, Obarenes y estribaciones meriodionales de Toloño. 


\section{BIBLIOGRAFÍA}

ABÁSOLO, J.A. 1975.

Comunicaciones de la época romana en la provincia de Burgos. Burgos.

ABÁSOLO, J.A., BARRIOCANAL, Y RODRÍGUEZ, J. 1982.

"Un interesante conjunto arqueológico de época romana: los yacimientos del área de Cubo de Bureba (Burgos)": Sautuola, III, pp. 139-169.

ABÁSOLO, J.A., LOZA, L.R., SÁENZ DE BURUAGA, J.A. 1983.

"Columna miliaria de Errekaleor ( Vitoria-Álava)" : Estudios de Arqueología Alavesa, 11, pp. 427-439.

ALBERTOS, M.L. 1970.

"Álava prerromana y romana. Estudio lingüístico": Estudios de Arqueología Alavesa, 4, pp. $107-223$.

ALBERTOS, M.L. 1974.

"El culto a los montes entre los Galaicos, Astures y Berones y algunas deidades más significativas": Estudios de Arqueología Alavesa, 6, pp. 147-157.

ALBERTOS, M.L. 1984 A.

"Lo que sabemos de las antiguas ciudades de Álava": Veleia, 1, pp. 267-270.

ALBERTOS, M.L. 1984 B.

"Onomástica personal en las inscripciones romanas de Álava": Congreso de Estudios Históricos: La formación de Álava, 650 aniversario del Pacto de Arriaga (13321982).Vitoria, pp. 33-61.

ALBERTOS, M.L. 1985.

"A propósito de algunas divinidades lusitanas": Symbolae Ludovico Michelena septuagenario oblatae. Vitoria, pp. 469-474.

ALDEA VAQUERO, Q., MARÍN MARTÍNEZ, T., VIVES GATELL, J. (DIR.) 1972.

Diccionario de Historia Eclesiástica de España. Madrid.

ARMENTIA, F. 1968.

"Labastida": Boletín de la Institución Sancho el Sabio, XII.

AZKARATE, A. 1988.

Arqueología cristiana de la antigüedad tardía en Álava, Guipúzcoa y Vizcaya. Vitoria.

BARÁIBAR, F. ( S.F.).

Lápidas, inscripciones y otros asuntos principalmente de Álava. Carpeta de manuscritos. 
BARÁIBAR, F. 1912.

"Museo Incipiente": Suplemento a la Memoria del curso 1911 a 1912, en el Instituto General y Técnico de Vitoria. Madrid.

BARANDIARÁN, I. 1968.

"Tres estelas del territorio de los Vascones": Caesaraugusta, 31-32, pp.199-225.

BARANDIARÁN, J.M.1928.

"Mari, o el genio de las montañas": Homenaje a D. Carmelo de Echegaray. San Sebastián, pp. 245-268.

BARANDIARÁN, J.M. Y COL. 1960.

El mundo en la mente popular vasca. ( Creencias, cuentos y leyendas). San Sebastián. BELTRÁN LLORÍS, M. 1987.

"La España celtibérica: La II Edad del Hierro en el Valle del Ebro": Historia General de España y América, I-2 : De la Protohistoria a la conquista romana, Madrid, pp. 257-295.

BERTOLDI, V. 1931.

"Problèmes de substrat": Bulletin de la Société Lingüistique de Paris, XXXII, pp. 93-184.

BLÁZQUEZ, J.M. 1962.

Religiones primitivas de Hispania,I: Fuentes literarias y epigráficas, Roma.

BLÁZQUEZ, J.M. 1975.

Diccionario de las Religiones Prerromanas de Hispania, Madrid.

BLÁZQUEZ, J.M. 1983.

Primitivas religiones ibéricas,II: Religiones prerromanas, Madrid.

BLÁZQUEZ, J.M. 1991.

Religiones en la España Antigua, Madrid.

CANTERA ORIVE, J. 1955.

San Felices de Bilibio, patrón de Haro (Logroño), Vitoria.

CANTERA ORIVE, J.1967.

"Labastida y Salinillas de Buradón": Catálogo Monumental Diócesis de Vitoria, I, Vitoria.

CARO BAROJA, J. 1950.

"Sobre el culto a los árboles y la mitología relacionada con él en la Península Ibérica": Homenaje a Don Luis de Hoyos Sáinz, V, II, pp. 65-74.

CARO BAROJA, J. 1973.

Los pueblos del Norte, San Sebastian. 
CARO BAROJA, J. 1974.

Ritos y mitos equívocos, Madrid

CARO BAROJA, J. 1976

Los pueblos de España, Madrid.

CARO BAROJA, J. 1980.

Sobre la religión antigua y el calendario del Pueblo Vasco, San Sebastián.

CASTRO, C, 1915.

Catálogo Monumental de España. Provincia de Álava. Madrid.

CEGARRA, J. 1990.

Vida e Historia de San Felices de Bilibio. Equipo Harense de Historia. Haro ( La Rioja).

CORTA, J.M. 1928.

"Vías romanas en Álava. Monumentos arqueológicos": Euskalerriaren Alde, 297298, pp. 326-350.

DE MIGUEL DE HERMOSA, A.R. 1992.

"Las comunicaciones en época romana en Álava, Navarra y La Rioja": Trabajos de Arqueología Navarra, 10, pp. 337-363.

DE VRIES, J. 1963.

La religion des celtes, Paris.

DONTENVILLE, H. 1948.

La Mythologie française, París.

DUMÉZIL, G. 1958.

L'ideologie tripartite des Indo-Européens, Bruxelles.

DUPRÉ, N. 1973.

“La place de la Vallée de l'Ebre dans l'Espagne romaine”: Mélanges de la Casa de Velázquez, IX, pp. 133-176.

DURAND, G. 1984.

Les structures anthropologiques de l'imaginaire, Paris.

ELIADE, M. 1981.

Tratado de historia de las religiones. Morfología y dinámica de lo sagrado, Madrid ( $1^{a}$ ed. en francés de 1949).

ELIADE, M. 1983.

Imágenes y Símbolos, Madrid. ( $1^{\mathrm{a}}$ ed. en francés de 1955). 
ELIADE, M. 1985.

Lo sagrado y lo profano, Barcelona. ( $1^{\text {a }}$ ed. en alemán de 1957).

ELORZA, J.C.1967.

"Ensayo topográfico de epigrafía romana alavesa": Estudios de Arqueología Alavesa, 2. pp. 119-185.

ELORZA, J.C. 1970.

"Estelas romanas en la provincia de Álava": Estudios de Arqueología Alavesa, 4, pp. 235-274.

ELORZA, J.C. 1972.

"Religiones del País Vasco-Navarro en época romana": Estudios de Deusto, XX, 46, pp. 357-366.

EMBORUJO, A. 1985.

Caristios y Várdulos según las fuentes escritas (Época prerromana y altoimperial). Vitoria (Memoria de licenciatura dactilografiada).

ESPINOSA, U. 1986.

Epigrafía romana de La Rioja. Logroño.

FERNÁNDEZ MEDRANO, D. 1948.

"Guía Sumaria y Provisional del Museo Arqueológico de Alava": Ikuska, II.

FERNÁNDEZ GUERRA, A. 1883.

"Geografía romana de Álava": Boletín de la Real Academia de la Historia, III, pp. 22-33.

FLÓREZ, H. 1768.

La Cantabria. Madrid.

FLUTRE, L. 1957.

"Recherches sur les Éléments prégaulois dans la toponymie de la Lozère": Annales de l'Université de Lyon, 20.

FRAZER, J.G. 1981.

La rama dorada: magia y religión, México ( $1^{\mathrm{a}}$ ed. en inglés de 1890).

GALDÓS, R., RUIZ URRESTARAZU, E.1983.

"Montes y valles": Álava en sus manos, Vitoria, pp. 41-72.

GARCÍA FERNÁNDEZ, E; LÓPEZ LÓPEZ DE ULLÍBARRI, F; DÍAZ DE DURANA, J.R. 1990

Labastida en la Edad Media: poblamiento y organización político-administrativa (s.X-XIII), Vitoria-Gasteiz. 
GONZÁLEZ RODRIGUEZ, M. C. 1986.

Las unidades organizativas indígenas del área indoeuropea de Hispania. Anejo de Veleia, 2. Vitoria-Gasteiz

GONZÁLEZ RODRÍGUEZ, M.C. 1988.

"Indígenas y romanos en el territorio del País Vasco actual": II Congreso Mundial Vasco, I: De los orígenes a la cristianización, San Sebastián, pp. 143-162.

GORROCHATEGUI, J. 1984.

Onomástica indígena de Aquitania, Bilbao.

GOVANTES, A.C. 1846.

Diccionario Geográfico - Histórico de España. Sección II. Madrid.

HERGUETA, D. 1906.

Noticias Históricas de la Muy Noble y Muy Leal Ciudad de Haro, Logroño.

HÜBNER, E. 1869.

Corpus Inscriptionum Latinarum (CIL). II: Inscriptiones Hispaniae Latinae. Berolini HÜBNER, E. 1892.

Supplementum, II: Inscriptionum Hispaniae Latinarum. Berolini.

LARRAÑAGA, K., AZKARATE, A. 1988.

"La cristianización del País Vasco. Estado de la cuestión y supuestos metodológicos para la redefinición de los términos de un debate secular": II Congreso Mundial Vasco, I: De los orígenes a la cristianización. San Sebastián, pp. 325-366.

LE ROUX, F.

"La religion des Celtes": Histoire des Religions, I. Paris, pp. 780-840.

LLANOS, A. 1988.

"Poblado de la Hoya ( Laguardia, Álava)", Burillo, F., Pérez Casas, J.A., De Sus, M.L. Celtíberos, Zaragoza, pp. 68-71.

LYNCH, C.H., GALINDO, P. 1950.

San Braulio obispo de Zaragoza (631-651) su vida y sus obras, Madrid.

MADOZ, P. 1846.

Diccionario Geográfico-Estadístico-Histórico de España y sus posesiones de ultramar, IV. Madrid.

MALUQUER DE MOTES, J. 1982.

"Pueblos celtas": Menéndez Pidal, R. ( dir.) Historia de España. España primitiva. La Historia prerromana., I, III, Madrid, pp. 3-194.

MARCO SIMÓN, F. 1987.

"La religión de los celtíberos": I Simposium sobre los celtíberos (Daroca, 1986). Zaragoza, pp. 55-74. 
MARTÍN BUENO, M.A.; MOYA VALGAÑóN, J.G. 1972.

"El puente Mantible": Estudios de Arqueología Alavesa, 5, pp. 165-182.

MELENA, J.L. 1985.

"Salama, Jálama y la epigrafía latina del antiguo Corregimiento": Symbolae Ludovico Mitxelena septuagenario oblatae. Vitoria, pp. 475-530.

MENÉNDEZ PELAYO, M. 1965.

Historia de los heterodoxos españoles, Madrid.

MERINO URRUTIA, J. B. 1946.

"Notas sobre la necrópolis de Bilibio ( Haro)": Archivo Español de Arqueología, 65 , pp. 358-360.

MERINO URRUTIA, J.B.1977.

"De Arqueología riojana": Berceo, 93, pp. 259-287.

MINGUELLA, T. 1919.

Valvanera. Imagen y santuario, Madrid.

MONREAL, L.A. 1989.

Eremitorios ruprestres altomedievales, Bilbao.

PEÑAS TRUQUE, M.A. 1986.

"Los dioses de la montaña": Bermejo Barrera, J.C. Mitología y mitos de la Hispania prerromana, cap. V, pp. 117-140, Madrid.

PÉREZ DE URBEL, J. 1934.

Los monjes españoles en la Edad Media, Madrid.

PORTILLA, M., EGUÍA, J. 1968.

"Arciprestazgos de Treviño-Albaina y Campezo": Catálogo Monumental Diócesis de Vitoria, I, Vitoria.

PRESTAMERO, L. ( S.F.)

Carpeta de manuscritos. Archivo Provincial de Álava.

PRESTAMERO, L. 1792.

"Camino militar romano que pasaba por la Provincia de Álava": Gónzalez de Echávarri, V. 1900. Alaveses Ilustres, I, pp. 271-329.

RAMÍREZ, J.L. 1981.

"Las creencias religiosas, pervivencia última de las civilizaciones prerromanas en la Península Ibérica": La religión romana en Hispania., pp. 225-252.

RODRÍGUEZ COLMENERO, A., LOURENCO FONTES, A. 1980.

"El culto a los montes entre los Galaico-Romanos": Actas do Seminario de Arqueologia do Noroeste Peninsular, III, pp. 21-35. 
ROSTAING, CH. 1950.

Essai sur la Toponymie de la Provence (depuis les origines jusqu'aux invasions barbares). D'Artrey, Paris.

RUBIO ALIJA, J. 1955.

"Nuevas inscripciones romanas": Zephyrus. VI, pp. 295-299.

SACAZE, J.1885.

"Les anciens dieux des Pyrénées": Extrait de la Revue de Comminges.

SACAZE, J. 1892.

Inscriptions antiques des Pyrénées. Toulouse.

SÁENZ DE BURUAGA, A. 1988.

"Nuevas inscripciones de época romana en Álava": Estudios de Arqueología Alavesa, 16, pp. 531-556.

SALAS, J., REDONDO, J.A., SÁNCHEZ, J.L. 1983.

"Un sincretismo religioso en la Península Ibérica: Júpiter Salutorio-Eaeco"Norba, IV, pp. 243-261.

SALINAS DE FRÍAS, M. 1982.

"La religión indígena del Oeste de la Meseta: los Vettonnes": Studia Zamorensia, 3, pp. 325-340.

SALINAS DE FRÍAS, M. 1985.

"La religión indígena de la Hispania central y la conquista romana": Studia Zamorensia, VI, pp. 307-331.

SALINAS DE FRÍAS, M. 1986 ( 1982).

La organización tribal de los Vettones, Salamanca.

SÁNCHEZ ALBORNOZ, C. 1931.

"De Birovesca a Suessatio". Revista de la Biblioteca, Archivo y Museo del Ayuntamiento de Madrid, 29.

SÁNCHEZ ZURRO, D. (ED.) 1989.

Pascual Madoz. Álava-Araba 1845-1850. Juntas Generales de Álava. Salmanca.

SANTOS YANGUAS, J. 1989.

Los pueblos de la España Antigua. Historia 16. Madrid.

SANTOS YANGUAS, J. 1991.

"De la Edad de los Metales a la época romana": Manual de Historia de España, 1, Prehistoria. Historia Antigua. Historia 16. Madrid, pp. 103-249. 
SCHULTEN, A. 1959.

Geografía y Etnografía antiguas de la Península Ibérica, Madrid.

SOLANA SÁINZ, J.M. 1974.

Los Autrigones a través de las fuentes literarias. Anejos de Hispania Antiqua, I. Vitoria.

SOLANA SÁINZ, J.M. 1978.

Autrigonia romana. Zona de contacto Castilla-Vasconia, Valladolid.

SOLOVERA, M.E., GARABITO, T. 1978.

"La religión indígena y romana en la Rioja de los Berones": Hispania Antiqua, VIII. pp. 143-199.

SOPEÑA, G. 1987.

Dioses, ética y ritos. Aproximaciones para una comprensión de la religiosidad entre los pueblos celtibéricos, Zaragoza.

TARACENA, B. 1940.

"La antigua población de la Rioja": Archivo Español de Arqueólogia, XIV, pp.157-176.

TARACENA, B. 1942.

"Restos romanos en la Rioja": Archivo Español de Arqueología, XV, pp. 17-46.

TARACENA, B. 1982.

"Los pueblos celtibéricos": Menéndez Pidal, R. (dir.). Historia de España. España primitiva. La Historia prerromana., I, III, Madrid, pp. 195-299.

TOUTAIN, A. 1967.

Les cultes païens dans l'Empire romaine, III, Les cultes indigènes nationaux et locaux, Roma (reimp. ed. de Paris 1917-1918).

TOVAR, A. 1955.

"Topónimos con -nt- en Hispania y el nombre de Salamanca": $V$ Congreso Internacional de Ciencias Onomásticas. Salmanca.

UBIETO ARTETA, A. 1976.

Cartulario de San Millán de la Cogolla (759-1076). Valencia.

VALDIVIELSO, R. M. 1986.

"Los orígenes de un culto en los montes de La Rioja: Valvanera": Segundo Coloquio sobre Historia de la Rioja (Logroño, 1985), I. Colegio Universitario de la Rioja, pp. 219-232.

VÁZQUEZ DE PARGA, L. 1943.

Vita Sancti Aemiliani. Madrid. 
REFERENCIAS AL CULTO PRECRISTIANO DEL MONTE BILIBIO (LA RIOJA)

VENDRYÈS, J. 1948.

"La religion des Celtes": Les religions de l'Europe ancienne, III. Paris, pp. 239-320.

VILLACAMPA, M.A. 1980

Los Berones según las fuentes escritas, Logroño.

VIVES, J. 1971.

Inscripciones Latinas de la España Romana. (ILER). Barcelona.

VV.AA.1802.

Diccionario Geográfico-Histórico de España. Real Academia de la Historia. Madrid. VV.AA. 1987.

Carta Arqueológica de Alava., 1. Instituto Alavés de Arqueología. Vitoria 
